How to cite this article: Resch M, Bühler J, Schachler B, Kunert R, Meier A, Sumper A. Technical and economic comparison of grid supportive vanadium redox flow batteries for primary control reserve and community electricity storage in Germany. Int $J$ Energy Res. 2018;1-21. https://doi.org/10.1002/er.4269

This is the link to published open access read only version of the article:

\title{
https://rdcu.be/ba3Gx
}




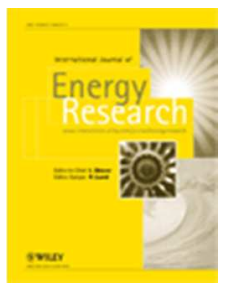

\section{Technical and Economic Comparison of Grid Supportive Vanadium Redox Flow Batteries for Primary Control Reserve and Community Electricity Storage}

\begin{tabular}{|r|l|}
\hline Journal: & International Journal of Energy Research \\
\hline Manuscript ID & Draft \\
\hline Wiley - Manuscript type: & Research Article \\
\hline Date Submitted by the Author: & $\mathrm{n} / \mathrm{a}$ \\
\hline Complete List of Authors: & $\begin{array}{l}\text { Resch, Matthias; Universitat Politècnica de Catalunya, Departament } \\
\text { d'Enginyeria Elèlectrica } \\
\text { Bühler, Jochen; Reiner Lemoine Institut } \\
\text { Schachler, Birgit; Reiner Lemoine Institut } \\
\text { Kunert, Rita; Reiner Lemoine Institut } \\
\text { Meier, Andreas; Reiner Lemoine Institut } \\
\text { Sumper, Andreas; Centre d'Innovaciò Tecnològica en Convertidors Estàtics } \\
\text { i Accionaments (CITCEA-UPC), Universitat Politècnica de Catalunya, ETS } \\
\text { d'Enginyeria Industrial de Barcelona. , Departament d'Enginyeria Elèctrica. }\end{array}$ \\
\hline Keywords: & $\begin{array}{l}\text { vandium redox flow battery models, primary control reserve, community } \\
\text { electricity storage, grid supportive, reactice power control }\end{array}$ \\
\hline
\end{tabular}

\section{SCHOLARONEm \\ Manuscripts}




\title{
Technical and Economic Comparison of Grid Supportive Vanadium Redox Flow Batteries for Primary Control Reserve and Community Electricity Storage
}

\author{
Matthias Rescha,b, Jochen Bühler ${ }^{\mathrm{a}}$, Birgit Schachler ${ }^{\mathrm{a}}$, Rita Kunert ${ }^{\mathrm{a}}$, Andreas Meier ${ }^{\mathrm{a}}$, \\ Andreas Sumper ${ }^{b}$ \\ ${ }^{a}$ Reiner Lemoine Institut $g \mathrm{GmbH}$, Rudower Chaussee 12, 12489 Berlin, Germany \\ ${ }^{b}$ Centre d'Innovació Tecnològica en Convertidors Estàtics i Accionaments (CITCEA-UPC), \\ Departament d'Enginyeria Elèctrica, Universitat Politècnica de Catalunya, ETS d'Enginyeria \\ Industrial de Barcelona, Av. Diagonal, 647, Pl. 2. 08028 Barcelona, Spain
}

\begin{abstract}
Primary control reserve and maximising self-consumption are currently two of the main applications for large scale battery storage systems. In this study, these two applications are combined with a grid supportive behaviour by providing reactive power control and/ or peak shaving and fitted to a vanadium redox flow battery prototype installed in Southern Germany. Simulation models for the operation of the battery storage system applying these applications are developed making it possible to analyse the battery operation for a longer period of time. Based on measured data from the prototype two battery models for two different time resolutions (1-s, 1-min) are presented in detail. The operation strategy model for primary control reserve comprises the so called degrees of freedom used to reduce the energy needed to recharge the battery. The operation strategy to maximise self-consumption is based on an adaptive persistence forecast. The technical assessment of both applications shows that the use of the degrees of freedom can reduce the energy to recharge the battery by $20 \%$. In the case of self-consumption the curtailment losses due to peak shaving can be kept under $1 \%$. The economic assessment, however, indicates that even for the most promising primary control reserve cases the investment costs of vanadium redox flow batteries must be reduced by at least $30 \%$ in order to break even. The economic findings also show that the negative impact of a grid supportive behaviour additionally to its primary purpose are less than $1 \%$ of the revenues. Finally, the model for the operation strategy for a grid supportive primary control reserve was validated in a field test revealing a relative error of $2.5 \%$ between the simulated and measured state of charge of the battery for a multi-week time period.
\end{abstract}

Keywords: vandium redox flow battery models, primary control reserve, community electricity storage, grid supportive

Email address: matthias.resch@upc.edu, Tel. +491604154188 , Corresponding author (Matthias Resch) 


\section{Introduction}

The highest revenue potential for market based applications of battery storage systems (BSS) lies in the primary control reserve (PCR) market, whereas the highest electricity cost reduction potential lies in maximising self-consumption of renewable energy production, specifically for households [1. Therefore, many BSS projects focus on these two potential business cases, especially in Germany [1 7 but also world-wide 8. Large scale (or pooled) BSS applying self-consumption maximisation can be called community electricity storage (CES) [9]. [10, 11] show that CES have the potential to lower the levelised costs of electricity considerably compared to single households using PV residential storage systems (e.g. $66 \%$ reduction for a 60 -household community in the UK [10]). Therefore, several studies examine CES as potential alternative for residential PV storage systems also in Germany [5-7. All large scale BSS projects that apply both mentioned applications realised until now in Germany use lithium-ion batteries. Although the vanadium redox flow technology is the second most promising technology regarding possible price reduction 12 and the energy to power ratio can be adapted more easily it has not been considered yet. This study fills this gap by focusing on this battery technology. Similar to 13 for lithium-ion batteries a BSS model for a vanadium redox flow battery (VRFB) is created from empirical data to describe the electrical operation behaviour and energy efficiency of battery systems and validated in field test.

As shown in 1], BSS applying PCR and self-consumption maximisation should operate grid supportive when integrated in the distribution grid. Otherwise they may cause additional grid reinforcement costs 14. Thus, several studies concerning CES consider active power control via peak shaving [6, 7]. Nevertheless, none of the studies consider reactive power control, even though [15] highly recommends further studies on this issue. This is due to the fact that reactive power control from BSS is as a very easy and cost-effective way of controlling the grid voltage which has no or only very little effect on the state of charge (SOC) of the BSS, depending on the system design.

In this study, the grid supportive operation of the two control strategies is proposed. In the PCR-case with a reactive power control and in the self-consumption case with a combined active and reactive power control. The reactive power control is implemented in both cases as an autonomously operating voltage control strategy whereas the active power control is implemented as a peak shaving algorithm.

This study is based on an extensive review of operation strategies for PCR and selfconsumption maximisation of the same authors [1. It extends the work of previous studies: [16, 17] had the aim to identify the most profitable operating strategy to maximise self-consumption and [18 is a life-cycle-cost analysis of different storage technologies participating at the German PCR market.

The main contributions of this paper is a technical and economic comparison of a grid supportive PCR and self-consumption application for VRFB and two validated simulation models to calculate the operation strategy and their effect on the SOC of the VRFB. The models used for the assessment are based on measured data from a VRFB-prototype developed within the SmartPowerFlow (SPF) [19] project, similar to [13] for lithium-ion. Beyond the model of 13 , the presented simulation model is able to simulate unsymmetrical charging and discharging, reactive power control and incorporates so called degrees of freedom in the PCR operation strategy.

The VRFB-prototype comprises of the $200 \mathrm{~kW} / 400 \mathrm{kWh}$ VRFB CellCube FB200- 
400 DC from Gildemeister energy solution, a $630 \mathrm{kVA}$ inverter (SCS 630) developed by SMA AG and the SCADA battery management software from Younicos AG. It has been integrated and tested in a model region of the distribution system operator LVN in the south of Germany, further described in [20]. The simulation results of the most profitable operation strategy were verified in a field test. All measured data, as well as the grid topology and other parameters needed for a load flow calculation were developed within the SmartPowerFlow project.

The paper is structured as follows: In section 2 two different battery models based on the data obtained of the VRFB-prototype are presented. Both battery models are applied in simulation models of the two operation strategies described in detail in section 3. Additionally, the respective legal framework, the revenues and costs and further assumptions are discussed in this section. In section 4 the results of the field test during which the most promising application (PCR) was implemented at the SPF-prototype are discussed and used to verify the simulation model developed before. In the same section the core of this work presented: the technical and economic assessment of the two business cases. Finally, the conclusions are summarised in section 5.

\section{Battery Storage System Modelling}

The modelled $200 \mathrm{~kW} / 400 \mathrm{kWh}$ VRFB is able to operate in a four quadrant operation mode, with a theoretical apparent power of $630 \mathrm{kVA}$. The BSS has a pump managing system with four individual pumping circuits, that can be activated according to the needed power in $50 \mathrm{~kW}$ steps in order to reduce the self-consumption of the BSS.

According to 21] there are macro 22 24, micro [25] and molecular approaches, as the Molecular Dynamics method [26], to model VRFB. Most of these theoretic battery models, out of which some have been evaluated in the lab [21 23], aim to improve the battery efficiency or to increase its capacity. In contrast to these models, the aim of the presented BSS model is to analyse the battery operation at the PCR market and as CES as realistically as possible over a longer period of time (months). The model presented BSS are also used for the economic optimisation of the BSS and to analyse the interaction with the electrical grid and the resulting reactive power need. For market applications, like in this work, empirical (macro) models based on measured data to predict the future behaviour without consideration of physicochemical principles seem to be the most appropriate [21. Therefore, an empirical approach similar to [13] for lithium-ion batteries based on efficiency characteristics is chosen for the VRFB model. In contrast the VRFB model of [24], the BSS model could be verified along with the PCR application in a field test presented in subsection 4.1 .2 . Furthermore, the effect of the reactive power provision on the SOC of the VRFB is not considered in 24].

Depending on the application, different time resolutions are used in the BSS models. For PCR one second time-steps are appropriate to properly incorporate all degrees of freedom (DOF) described in [1]. As shown in [27, the BSS model for the self-consumption operation strategy should be simulated at least in one minute time-steps to avoid the neglect of short-term feed-in peaks. Therefore, two different BSS models are presented in this subsection: In subsection 2.1 a detailed VRFB-model based on the SPF-prototype for grid supportive PCR applications and in subsection 2.2 a simplified VRFB-model that can be applied for CES used to maximise self-consumption is presented. As VRFB already in operation have shown an extremely long working life (up to 270,000 full cycles) 
and self-discharge can be eliminated by storing the two electrolytes in different tanks [28, both effects are neglected in this study.

\subsection{Detailed Vanadium Redox Flow Model for Grid Supportive PCR Applications}

In this application, the SOC of the VRFB depends on the active power demand as a function of the grid frequency and the reactive power demand as a function of the voltage. The model has a time resolution of $1 \mathrm{~s}$; inverter and battery are modelled separately.

\section{Inverter model}

The losses occurring during the operation of the inverter can be distinguished into no-load losses and apparent power losses. No-load losses are losses independent of the apparent power caused mainly by switching losses of the insulated gate bipolar transistors of the inverter bridge. For the SMA inverter used in the SmartPowerFlow project these losses are $2.3 \mathrm{~kW}$. They were determined by measuring the DC power between battery and inverter at $0 \mathrm{~kW}$ active power and 0 kvar reactive power at the $\mathrm{AC}$ side. The apparent power losses are composed of the losses due to provision of active and reactive power. For the VRFB-prototype a stable 4-quadrant operation of $\pm 200 \mathrm{~kW}$ as well $\pm 400 \mathrm{kvar}$ has been tested and validated in the field, as shown in Fig. 1.

\section{[Fig. 1 about here.]}

To determine the active power losses, the active power was altered over the entire operating range of $\pm 200 \mathrm{~kW}$ and the apparent power was kept at a constant level of 0 kvar. The resulting active power losses for charging and discharging are depicted in Fig. 2. At low power ratings of less than $50 \mathrm{~kW}$, the efficiency of the inverter is between $85 \%-95 \%$ and for power ratings greater than $50 \mathrm{~kW}$ between $95 \%-98 \%$.

[Fig. 2 about here.]

The methodology to measure the reactive power losses is the same as for the active power losses: the AC-active power is set to $0 \mathrm{~kW}$, whereas the reactive power is varied over the whole operation area of \pm 400 kvar. The results of this measurement are shown in Fig. 3. The measuring point for a reactive power of 0 kvar corresponds to the abovementioned no-load losses of around $2.3 \mathrm{~kW}$. The losses increase with increasing reactive power and reach a maximum of approximately $9 \mathrm{~kW}$ with maximum reactive power.

[Fig. 3 about here.]

According to SMA 29 the apparent power losses of the inverter $\mathrm{S}_{\text {loss }}$ can be approximated with equation (1), as the losses are mainly dependent on the absolute value of the apparent current $I_{\mathrm{s}}$.

$$
S_{\text {loss }}=\sqrt{P_{\text {loss }}^{2}+Q_{\text {loss }}^{2}}
$$

where $\mathrm{P}_{\text {loss }}$ are the active and $\mathrm{Q}_{\text {loss }}$ the reactive power dependent losses. In between the measurement data, $\mathrm{P}_{\text {loss }}$ and $\mathrm{Q}_{\text {loss }}$ are approximated by linear interpolation. 


\section{Battery model}

For the modelling of the battery, the charge- and discharge characteristics were measured. The BSS was fully charged and discharged at various power levels as depicted in Fig. 4 and Fig. 5 The discharge was limited to $1 \%$ SOC to avoid a deep discharge. The deviations in the predefined charging and discharging powers can be attributed to various causes such as power drops due to an excessively high electrolyte temperature, the failure of a DC-DC converter inside the battery or incorrect control commands by the battery management system and can be neglected in the model as these effects can be attributed to the prototype status of the BSS.

[Fig. 4 about here.]

[Fig. 5 about here.]

The charging and discharging curves show that the BSS can only be charged or discharged with a constant power up to a certain SOC. After reaching this power dependant SOC limit, the charging or discharging power drops steadily. For example, a constant charging power of $200 \mathrm{~kW}$ can only be maintained during the time period $\mathrm{t}_{\mathrm{C}}$ up to a charge level of $62 \%$. From this point on which is called $\mathrm{SOC}_{\mathrm{C}}$, the charging power drops to $53 \mathrm{~kW}$ until the battery is fully charged. The energy supplied to the BSS up to the point $\mathrm{SOC}_{\mathrm{C}}$, is defined as $\mathrm{E}_{\mathrm{C}}$ (see Fig. 4). This also applies to the discharging process. The SOC from which the constant discharge power decreases is referred as $\mathrm{SOC}_{\mathrm{D}}$, the energy taken up to this point is called $\mathrm{E}_{\mathrm{D}}$ (see Fig. 5). To participate in the PCR market, the BSS has to provide the requested power reliably and without interruption. Thus, it can only be operated within the limits $\mathrm{SOC}_{\mathrm{C}}$ and $\mathrm{SOC}_{\mathrm{D}}$ for a given value of the pre-qualified power. The change of SOC within these limits is calculated in the model as follows:

$$
\begin{aligned}
& \text { Charge: } \\
& \triangle S O C=\left.S O C_{C} \cdot \frac{\Delta t \cdot P}{E_{C}}\right|_{P} \\
& \text { with } S O C_{i}, S O C_{f}<S O C_{C} \\
& \text { Discharge: } \\
& \Delta S O C=\left.\left(100-S O C_{D}\right) \cdot \frac{\Delta t \cdot P}{E_{D}}\right|_{P} \\
& \text { with } S O C_{i}, S O C_{f}>S O C_{D}
\end{aligned}
$$

where parameters $\mathrm{SOC}_{\mathrm{C}}$ and $\mathrm{E}_{\mathrm{C}}$ as well as $\mathrm{SOC}_{\mathrm{D}}$ and $\mathrm{E}_{\mathrm{D}}$ were derived from the characteristic curves. $\mathrm{SOC}_{\mathrm{i}}$ is the initial SOC before charging/discharging and $\mathrm{SOC}_{\mathrm{f}}$ the final SOC after charging/discharging. The parameters for charging and discharging powers between the measured values result from linear interpolation.

The charging and discharging curves were measured in the PCR mode where all four pumping circuits of the VRFB-prototype are active due to the fast response time that is necessary when providing PCR. The pumps consume $12 \mathrm{~kW}$. This power is taken directly 
from the grid and purchased at the intra-day market, as this is more cost effective than discharging the BSS. The validation of the 1-s-model is presented in subsection 4.1 .2 .

\subsection{Simplified BSS Modell}

In this section a simplified BSS model for the simulation of a CES requiring only one formula is presented in order to reduce computing time. As established earlier a time resolution of one minute is sufficient for modelling CES. Contrary to the PCR application, the auxiliary power for the pump management is now taken from the battery. This is due to the fact that in this business model energy from PV systems is used for the battery operation. Also contrary to the PCR application only the necessary amount of pumps is used for charging or discharging as the ramp time of the pumps does not have a negative effect on this business case. In the simplified BSS model reactive power provision can not be modelled, and are calculated ex post. The energy needed for the provision of reactive power in the CES case is covered by transactions with the energy market. To obtain a formula for an exponential fit function with two terms, the non-linear least square method was applied. The efficiency curve, the equation of the fit function with $95 \%$ confidence bounds as well as the evaluation of the goodness of the fit are depicted in Fig. 6.

$$
\text { [Fig. } 6 \text { about here.] }
$$

As the charging power $P_{A C_{C}}$ or discharging power $P_{A C_{D}}$ might be different, according to [30] the SOC of the BSS can be calculated using an AC-power dependent round trip efficiency $\eta_{A C}$.

$$
\eta_{A C}\left(P_{A C_{C} / A C_{D}}\right)=\sqrt{\eta_{A C}\left(P_{A C_{C}}\right)} \cdot \sqrt{\eta_{A C}\left(P_{A C_{D}}\right)}
$$
3.2

This 1-min-model is used to simulate the grid supportive CES presented in subsection

\section{Methodology of the Techno-Economic Assessment}

The aim of the two methodologies presented in this section is to identify a grid supportive operation strategy for the battery prototype which guarantees the most lucrative participation at the PCR market subsection 3.1) or the application as a CES to maximise self-consumption subsection 3.2). Basis of the economic analysis is a life cycle cost analysis, as decribed in detail by 31. For this analysis the system design of the BSS is given hence the capital expenditures (CAPEX) is fixed. Furthermore, disposal costs are neglected, as at the end of the life cycle the electrolyte of a VRFB can still be used and earn revenues 32 .

\subsection{Grid Supportive Application of the Battery Storage System at the Primary Control Reserve Market}

The operation strategy is based on a frequency data analysis which ensures the $100 \%$ availability required by the TSO during the entire period primary control reserve and voltage control services are provided. 


\subsubsection{Assumptions}

The economic analysis is based on the legal framework of the PCR market, the bidding prices for PCR, the prices for the energy needed to recharge the battery as well as the CAPEX and operational expenditure (OPEX) of the BSS.

\section{Legal framework}

On the European level the regulations concerning PCR are [33 36] and on the national level [37 39]. There are also several technical regulations [40 43] on the national level as well as market rules [44. An extensive overview of the PCR regulations on European level is given by [45. For more details concerning BSS providing PCR in Germany [2] and 11 may be consulted.

\section{Revenue Stream and Expenses during Operation}

The revenues that can be achieved at the PCR market are determined by one's own bidding strategy as well as the structure and costs of the competitors [46. In this paper the bidding strategy is simplified as it is assumed that the BSS can provide PCR for 50 weeks per year (corresponding to 50 bidding periods) 4]. All data used in this study refer to the year 2015. Although the historical PCR prices fluctuate considerably in the course of the year, the more stable weekly average yearly values have risen slightly in the last three years [47]. For this work a yearly weekly average of $3500 \mathrm{EUR} / \mathrm{MW}$ is assumed during the entire lifetime of the BSS 48. Although there may be up to $150 \mathrm{MW}$ prequalified BSS systems in the German PCR market at the end of 2017, this may only have a minor effect on the yearly weekly average price, as 49] calculated that up to a power of $250 \mathrm{MW}$ the average bidding price would decrease by only $6 \%$. Therefore, this work, as well as most of the related studies 2, 4, assumes a constant yearly revenue stream over the BSS lifetime.

Expenses during PCR provision arise from the necessity to keep the battery charge level between certain limits, to ensure that the power demanded can be supplied at any time, as discussed in subsection 2.1. The energy that is needed to correct the charge level is traded at the intra-day market. The medium-term development of the intra-day market is hard to predict. Therefore, the annual average price for the 15-minute product of $33.09 \mathrm{EUR} / \mathrm{MWh}$ is used here. 50. Additionally, a handling fee of $2 \mathrm{EUR} / \mathrm{MWh}$ has to be added 51]. As stated in subsection 2.1, the auxiliary energy to run the pumping system generates furher expenses and is as well traded at the intra-day market. For further simplification it is assumed that the energy can always be traded and that the annual average intra-day price for a 15-minute product is constant. Based on [52 a value-added tax of $19 \%$ on costs and revenues as well as an electricity tax on the traded energy of $20.50 \mathrm{EUR} / \mathrm{MWh}$ has be taken into account. The tax and duty charge for electricity storage is currently in dispute, the energy tax has to be paid in any case [53. Finally, the costs for the metering point operation have to be taken into account and are set to $508.86 \mathrm{EUR} /$ year [54].

\section{Frequency data}

In order to determine the correction limits of the SOC, further explained in subsection 3.1.2 worst case scenarios were analysed. For this, particularly over- and under-frequent months from frequency data provided by the Swissgrid AG were used. Swissgrid AG, the 
Swiss transmission grid operator, as a result of a comprehensive frequency data analysis, identified a representative heavy and a weak load month. The data show an average overfrequency behaviour during the heavy-load month, resulting in higher battery charging powers than in average months. The heavy-load month as well shows a stronger frequency fluctuation than the weak-load periods, due to greater load gradients. Therefore, an extreme under-frequent monthly time-series was synthesised by mirroring the heavy-load time-series on the $50 \mathrm{~Hz}$ axis. The derived set of two heavy-load monthly time series can be considered the worst-case scenarios form SOC control point of view.

The economic analysis is based on the frequency data of the weak-load month given that this month's frequency time series is approximately normal distributed, as is true for long term frequency time series [4, 55. Therefore, the charged and discharged PCR power of the BSS is balanced on average. [56, 57]. The economic analysis was as well carried out and verified using frequency data from the year 2013, giving very similar results and therefore not further discussed.

\section{BSS Parameters}

The minimum offered power at the German PCR market is $1 \mathrm{MW}$. As the here considered VRFB-prototype has a maximum power of $200 \mathrm{~kW}$, a pooling of the battery is analysed. Pooling entails additional costs for additional infrastructure. Those additional costs are neglected in this study due to missing literature concerning this issue. However, pooling increases CAPEX and OPEX of the 1-MW pooling unit because the largest BSS unit needs to be redundant [43]. CAPEX and OPEX of the BSS are further discussed in subsection 3.3 .

\subsubsection{Modelling of the Operation Strategy}

All parameters that have to be determined for this operating strategy are schematically depicted in Fig. 7. The optimisation of the battery optimisation is mainly a maximisation of the PCR revenues and a minimisation of expenses for trading correction energy at the intra-day market. In order to achieve this the available charging/discharging power has to be allocated between power that is pre-qualified at the PCR market and power that is used to adjust the charging level of the battery and the SOC limits at which intra-day trades are triggered have to be determined.

[Fig. 7 about here.]

The pre-qualified power $P_{p q}$ determines the theoretical revenues and the usable capacity of the BSS. As described in section 2.1 the power of the BSS is only constant within a certain power dependant SOC range. The lower and upper limit of this interval is defined as availability limit $S O C_{a v, \min }$ and $S O C_{a v, \max }$. Outside these availability limits the BSS does not reach its full power, thus limiting the usable capacity to the capacity interval within these limits.

To ensure that the SOC stays within the availability limits, energy is traded at the intra-day market. This transaction increases or decreases the active power with a delay of 30 minutes for the delivery period of 15 minutes [58] by the contracted value, and is defined as the DOF "schedule transactions". Besides this cost-generating DOF there are additional DOF that can be used to keep the SOC close to the target SOC at no extra costs: "dead-band", "optional over-fulfilment" and "permissible operating range". These DOF are as well integrated in the simulation model, as depicted in Fig. 8. 
[Fig. 8 about here.]

The $\mathrm{P}(\mathrm{f})$-characteristic, as defined in [41, is the basis of provision of PCR and the active power control of the BSS. As described in detail in [1, the DOF can be used to regulate the SOC by deviation of the required PCR power $P_{P C P}$, resulting in a new $P_{P C P, \text { new }}$. The DOF "schedule transactions" is triggered when the SOC surpasses a threshold defined as correction limits $S O C_{\text {corr }}$. Therefore, the SOC interval between $S O C_{c o r r, \max }$ and $S O C_{c o r r, \min }$ is narrower than the interval between the availability limits as it has to be secured that during the 30 min delay the SOC does not surpass the availability limits (see Fig. 7). For the three DOF free of charge the actual SOC of the time-step and the set target value $S O C_{\text {opt }}$ (in this study set to $60 \%$ due to the low BSS efficiency), as well as the absolute value the of frequency $f$ and the direction of the actual frequency deviation $\Delta f$ are essential inputs. All DOF can be used separately or combined.

The "dead-band" can be applied for $50 \mathrm{~Hz} \pm 0.01 \mathrm{~Hz}$ and $P_{P C P, \text { new }}$ is calculated as follows:

$$
P_{P C P, \text { new }}=\frac{\Delta f}{0.2 \mathrm{~Hz}} \cdot P_{p q}
$$

If the DOF "optional over-fulfilment" is used, the $P_{P C P}$ according to the $\mathrm{P}(\mathrm{f})$ characteristic is exceeded by $20 \%$.

$$
P_{P C P, \text { new }}=1.2 \cdot P_{P C P} .
$$

When making use of the "permissible operating range" the power gradient $\partial P_{P C P}$ is restricted to the permitted ramp (30 seconds until full activation), instead of using the fast reaction time of BSS.

$$
\max \left(\left|\partial P_{P C P}\right|\right)=\frac{P_{p q}}{30} .
$$

This DOF is stopped in case of a change of sign between two time-steps (e.g. change from charge to discharge)

The final $P_{P C P, \text { new }}$ value calculated after applying all three DOF free of charge is limited to $P_{p q}$.

$$
\left|P_{P C P}\right| \leq P_{p q} .
$$

Finally, the DOF "schedule transactions" is activated if the availability of the BSS is endangered.

As stated before, the maximum available power of the BSS must be divided between the power to correct the SOC and the power offered at the PCR market. Critical is the 30 -min period until the transaction is effective. In view of the depicted efficiency losses of the storage system and the asymmetrical position of the availability limits, the upper and lower correction limits are to be determined individually. In order to determine the correction limits, the assumption was made that the availability limits should not be exceeded even in a particularly over- or under-frequent month, even if the SOC is already at the corresponding correction limit at the beginning of the month. The heavy 
load month was used to determine the upper availability and correction limit and the synthesized under-frequent month was used for the lower limits.

The voltage time series needed as input data for the reactive power control is taken from measurements from the year 2013 at the point of common coupling of the BSS. Two worst case months were identified, each with a particularly high or low reactive power consumption corresponding to the annual average.

[Fig. 9 about here.]

To define the points of the $\mathrm{Q}(\mathrm{V})$-characteristic, shown in Fig. 9 , the maximum voltage limits according to DIN EN 50160 of \pm 0.1 p.u. were taken as basis [59. Furthermore, a measurement uncertainty of \pm 0.01 p.u. was taken into account [60]. As a maximum voltage drop of 0.04 p.u. can be assumed [14, $\mathrm{V}_{4}$ is set to 1.05 p.u. (1.1 p.u. - 0.01 p.u. - 0.04 p.u.). In order to keep the $\mathrm{Q}(\mathrm{V})$-control stable a slope of the $11 \% / \mathrm{V}$ (phase-toground-voltage) is proposed by [61] which results in the value of $1.027 \mathrm{p} . \mathrm{u}$ for $\mathrm{V}_{3}$. Since the $\mathrm{Q}(\mathrm{V})$-characteristic is assumed symmetrical to the origin $61, \mathrm{~V}_{2}$ and $\mathrm{V}_{1}$ result. A $\mathrm{PT} 1-\mathrm{element}$ is assumed with an amplification factor $\mathrm{K}=1$ and a time delay of $\mathrm{T}=5 \mathrm{~s}$ 61 .

In order to maximise the net present value with this operation strategy, the maximum $P_{p q}$ that can be provided with the given BSS has to be determined. At the same time the availability of the BSS to provide PCR and reactive power control has to be assured at every time. For this reason $P_{p q}$ was varied in $5 \mathrm{~kW}$ steps and tested for the worst case scenarios described before.

\subsection{Grid Supportive Application of the Battery Storage System as Community Electricity Storage}

In analogy to the section before, first the legal framework is shortly discussed as well as the revenues and expenses based on locally measured generator and load data in subsection 3.2 .1 . Furthermore, the most profitable operation strategy to ensure selfconsumption maximisation with a CES is presented and implemented in the SPF project subsection 3.2.2.

\subsubsection{Assumptions \\ Legal framework}

Charges and levies for CES mainly depend on the ownership of the electrical grid to which the BSS is connected and on whether the electricity from the storage is consumed in the vicinity of the storage or supplied to a third party. This is shown in Fig. 10. The two bars on the right-hand side of figure show the expenses in case the BSS is connected to the public grid (case 3 and 4); the two columns on the left show the levies and charges in case the electricity is generated, stored and consumed in the vicinity of the storage without the use of the public network. These two distinctions (case 1 and 2) are divided according to whether they are self-consumption (case 1) or electricity supply from the CES operator to a third party consumer (case 2).

A comprehensive study reviews different possible business cases that can be applied to CES [5]. Furthermore, a guideline concerning the legal framework connected to these business cases is published by the German federal network agency 62. Although focussing on the EEG 2014, the guideline is still valid for the EEG which became effective in January 2017. 
[Fig. 10 about here.]

\section{Revenue Stream and Expenses during Operation}

The revenues in this business case are caused by a cost reduction strategy that takes advantage of the difference between cost of generation (feed-in tariff, FIT) and purchase price for electric energy. For this study a feed-in tariff of $0.1231 \mathrm{EUR} / \mathrm{kWh}$ and an electricity price of $0.2881 \mathrm{kWh} / \mathrm{EUR}$ are used [63, 64].

The expenses consist of the CAPEX and OPEX decribed in subsection 3.3 and the charges and levies discussed before. Only the theoretic best case and the two most promising scenarios which can be realised under the current legal framework are calculated:

(1) Theoretic best case (Th. best)

This case is the theoretical possible best case, which means that there is no FIT and no charges and levies incur. This scenario is highly unlikely today, yet could become reality in a post-FIT era after 2020 [65.

(2) Self-consumption best case (SC best)

In the case of a geographical proximity in which the consumers and the owners of the PV generator are not the same legal entity but use an own private grid, the self-consumption case applies. Therefore, only the full EEG-levy incurs (see column 1 in Fig. 100.

(3) Direct marketing best case (DM best)

If the storage operator and grid operator peruses a direct marketing model and sells energy to third party costumers within the own private grid, the EEG-levy and the VAT, business and corporation tax incur. The charges and levies that apply in this case are depicted in column 2 in Fig. 10.

\section{Load and Generator data}

The three scenarios described before are evaluated for the village in which the prototype of the SPF project is implemented, described in detail in [20. Within the village there are 441 individual loads. To model the consumption behaviour three different German standard load profiles in one-minute time steps are used. The distribution of the different profiles is as follows: 264 loads with a $\mathrm{H} 0$ household profile, 38 commercial loads with a G0 profile and 35 agricultural loads with a L0 load profile 66. Additionally, a real heat pump profile from [67] is used in four houses. The total yearly energy consumption of the village is $3.73 \mathrm{GWh}$. On the generator side the PV systems' accumulated nominal power of the 119 residential systems installed within this village is $2.0 \mathrm{MW}$. The PV power profile is based on measured data from 2013 and 2014 in one-minute steps connected on a near village $(10.1 \mathrm{~km})$ south oriented PV system. Based on calculations of 68 the diversity factor for the PV-systems, as defined in [69] is set to 0.85 .

\section{Sizing of the Community Electricity Storages}

Analogue to the optimal economical sizing of residential storage systems for $1 \mathrm{kWh}$ of storage capacity of the CES, a PV system size of $1 \mathrm{kWp}$ and a annual load demand of $1 \mathrm{MWh}$ is chosen for every system [70]. As the BSS is connected to the LV-side of the 
MV/LV-transformer, if possible all the loads and PV-systems of the same LV-level were gathered for one CES. This leads to a non-optimal sizing of the loads and PV-systems, but increases the hosting capacity of the LV systems and is therefore grid supportive, as the CES are also used for peak shaving as described in the following section. As the installed PV power is $2.0 \mathrm{MW}$, only the geographically closest loads with a total annual consumption of $2.3 \mathrm{GWh}$ were combined to 5 separate CES systems with the SPF prototype of $400 \mathrm{kWh}$ storage capacity to comply with the sizing rule described before.

[Fig. 11 about here.]

\subsubsection{Modelling of the Operation Strategy}

In order to assure a grid supportive behaviour of residential PV-storage systems the German government coupled the incentives for these storages with the condition on limiting the feed-in to $50 \%$ for the of the maximal PV power. Although these incentives are only granted for residential PV-storage systems, the $50 \%$ limit is used in this study to assure a better comparison with other studies. Preliminary studies by the authors of this paper indicate that the adaptive persistence forecast control strategy is most profitable from the storage owner's point of view [17, 20. This strategy secures the best results with regard to the performance indicators curtailment loss ratio ratio (CLR), self-consumption ratio (SCR) and self-supply ratio (SSR), as defined in [17. The methodology of the adaptive persistence forecast control strategy was adapted from the strategy initially designed for residential PV storage systems by [71, 72]: This strategy aims on minimising the daily feed-in energy and thus maximising the self-sufficiency and the profit. This is achieved by limiting the feed-in power dynamically, always taking the maximum feed-in boundary into account. The dynamic feed-in limit is ideally set each day based on the forecasts such that the battery is completely charged with the energy that exceeds the dynamic limit 72 .

For the load prediction 71 uses a method that assumes a load profile for the predicted weekday identical to the load profile of the weekday from the previous week. As the PV output has a stronger impact on curtailment losses and self-sufficiency rate than the load forecast, an elaborated method for the PV persistence forecast which is based on a moving prediction horizon as well as a on a long term and short term prediction relying on locally measured data of the PV system is used [71].

For every CES the profiles for the generator and load data is gathered and the prediction is performed only for the accumulated profiles. The resulting charging or discharging power is calculated for every minute time-step. The usable battery capacity is set between $1 \%$ and $99 \%$ of its nominal capacity of $400 \mathrm{kWh}$. For the simulation of the SOC, the simplified 1-min battery modell as described in section 2.2 is used to reduce computing time. Nonetheless, a yearly simulation of the 5 CES including a load-flow calculation of the whole model area takes 31 hours, although the year was partitioned in 16 periods and calculated in parallel on 8 cores with $2.9 \mathrm{GHz}$ and $32 \mathrm{~GB}$ RAM on a server with the model name HP ProLiant DL360p Generation 8 (Gen8). For each period the SOC of the 5 CES were set at $1 \%$ for the first time-step.

As with this simplified battery model only the active power is taken into account, it is assumed that the reactive power to provide the reactive power control based on the $\mathrm{Q}(\mathrm{V})$-characteristic is the same as if the BSS provides PCR and reactive power control. The BSS is connected in both cases to the LV busbar of the MV/LV transformer. 
These assumptions seems reasonable, as the active power of the two different operation strategies has very little influence on the voltage due the low $\mathrm{R} / \mathrm{X}$-ratio on this point of common coupling (PCC) and can therefore be neglected.

\subsection{Economic Assumptions}

In this section the CAPEX and the OPEX along with other economic parameters applying for both business cases are presented briefly.

\section{Capital expenditures}

According to 73 , the formula to calculate the investment costs $\mathrm{I}_{0}$ (=CAPEX) for a given power $\mathrm{P}_{\max }$ and a given capacity $\mathrm{E}_{\max }$ is:

$$
I_{0}=c_{P} \cdot P_{\max }+c_{E} \cdot E_{\max }+C
$$

where $c_{P}$ are the specific cost of the power electronics, $c_{E}$ are the specific cost of the components needed for the capacity and $\mathrm{C}$ are the costs for the system periphery (e.g. site costs,..). C can not necessarily be scaled with the system design and are very project specific [4]. For vanadium redox flow large scale batteries, which are hardly established in the market, there is currently a large range of costs difficult to generalise $74-76$. The costs used in this study display the wide cost range found in the literature for commercial BSS when adapetd to the same configuration as in the SPF project (see Table 1).

\section{[Table 1 about here.]}

\section{Additional Economic Parameters}

For the yearly operating expenditures a value of $2 \%$ of the minimal $I_{0}$ is assumed, which includes the replacement costs of components during the life time 79. The internal rate of return is set to $4 \%$ [4] and the lifetime for the BSS to 15 years [4, 79].

\section{Techno-Economic Assesment and Validation of the Simulated Results in a Field Test}

First, the technical results of the simulation of the two operation strategies are discussed in this section and it is concluded with an economic comparison of both business cases applied to the SPF prototype. Furthermore, the detailed battery model (see subsection 2.1] and grid supportive PCR operation mode is tested in the field and verified.

\subsection{Operation Strategy: Grid Supportive Primary Frequency Control}

In this operation strategy the worst-case time series for frequency and voltage at the PCC were used for an iterative simulation, by changing the pre-qualified power. Thus, the upper and lower correction limit as well as the corrective energy can be calculated. From an economic point of view, the combination of pre-qualified power, upper and lower correction limits is optimal, when the PCR revenue are maximised and at the same time the costs of the correction energy are minimised. 


\subsubsection{Results of the Parameter Determination for an Profit Maximizing Operation}

With the brute force optimisation described in section 2 , the parameters summarized in Table 2 result as those with the maximum difference between PCR-revenue and corrective energy costs. For a pre-qualified power higher than $P_{p q}=175 \mathrm{~kW}$ the availability of the BSS to provide PCR and reactive power control can not be ensured.

[Table 2 about here.]

The results in Table 2 show that both the availability and the correction limits are arranged asymmetrically around the SOC of $50 \%$. Due to the efficiency losses during charging and discharging of the battery, the target value and the correction limits are just below or above the SOC of $50 \%$. Furthermore, it can be seen that due to the battery losses, the distance between the upper correction and availability limit is substantially less than the distance between the lower correction and availability limit.

\subsubsection{Validation of the Battery Model and the Operation Strategy in the Field}

A multi-week field test with the determined parameters demonstrates the feasibility of grid-supportive PCR operation strategy (Fig. 12). During the whole time, reactive power according to the $\mathrm{Q}(\mathrm{V})$-characteristic is provided (red curve upper graph). As can be seen in the upper graph, the maximum requested frequency dependant PCRpower $\mathrm{P}(\mathrm{f})$, is only $20 \mathrm{~kW}$, or $8,5 \%$ of the pre-qualified power during this period (grey curve). However, this was expected according to the stochastic distribution of frequency fluctuations. $\mathrm{P}_{\mathrm{AC}}$ however shows the active power measurement at the point of common coupling of the battery system. It can be seen that during the field test the DOF are exclusively applied to charge the battery.

This unsymmetrical application of the DOF is also reflected in the SOC (Fig. 12 , lower graph). Due to the low system efficiency, the used battery capacity interval is narrow and oscillates around the lower correction limit, the target value of $60 \%$ is never reached or exceeded.

[Fig. 12 about here.]

For the validation of the detailed battery system model (section 2.1 , the battery parameters were measured during the two weeks mentioned above in the grid-supportive PCR operating mode providing active and reactive power. Ex-post, the SOC curve was simulated by using the calculated active and reactive power as input parameters according to the measured frequency and voltage at the PCC, as depicted in Fig. 8 . For the entire measurement period, a very good match between simulation and measurement was achieved, with a relative error of $2.5 \%$ Fig. 12 , lower graph). However, the simulated SOC is usually slightly ahead of the measured SOC. This is due to an inertia of the SOC measurement, which is not represented in the model. In this BSS prototype, the SOC is measured via the open circuit voltage of a stack to which no load is connected. Since the electrolyte of the stacks connected to the load has to be mixed with the electrolyte in the tanks before it is pumped into the idle stack, the changed SOC is measured with a certain delay. This delay was quantified to vary between 0-19 min.

The evaluation of the field measurements shows that the overall system efficiency, especially at low power is not very high: The BSS efficiency over the period depicted is $30 \%$, taking into account the pumping power, it is even lower with approximately $23 \%$. 


\subsubsection{Evaluation of the Degrees of Freedom and the Grid Supportive Behaviour}

It is not possible to provide PCR with the analysed BSS without the application of the DOF "schedule transactions". Therefore, an operating mode for the discussed gridsupportive operation strategy which uses this DOF only is used as a reference scenario in order to evaluate the efficiency of the other optional and cost neutral DOF and the costs incurred by the reactive power provision. As depicted in Fig. 13, the comparison of the individual DOF shows that they differ significantly in their contribution to reduce corrective energy that has to be traded at the intra-day market with the DOF "schedule transactions". When all cost neutral DOF are employed, the corrective energy can be reduced by approximately $20 \%$.

[Fig. 13 about here.]

However, the economic effects of the DOF are low, as the net revenues only increases as follows: "dead-band" $0.9 \%$, "optional over-fulfilment" $1.1 \%$ and "permissible operating range" $0.08 \%$. If all optional DOF are used, the delta net revenues sum up to $2.1 \%$ or a monthly extra revenue of 45.89 EUR. Although, in one third of the simulated timesteps the battery has to be charged via intra-day transactions and over $40 \%$ of the total energy is due to corrective energy, the total costs of the corrective energy (with all DOF) amount only to $7 \%$ of the revenues. For this same reason, the impact of the provision of reactive power is minimal. This results from a simulation with all DOF, but without a reactive power supply (right column in Fig. 13). For the analysed PRL prototype, the monthly expenditures increase by only 14 EUR for additional correction energy needed to provide this service. It can be concluded that the resulting additional cost burden for a grid supportive behaviour of a BSS system providing PCR is very small.

\subsection{Operation Strategy: Grid Supportive Community Electricity Storage}

In this section, the technical results of the simulation of the SPF prototype applied as a CES with the simplified battery model (see subsection 2.2 ) are discussed. In the upper graph of Fig. 14 the power flows of CES generating the highest profit (CES 1) for the week of highest irradiation are depicted, and the lower graph shows the corresponding SOC curve.

[Fig. 14 about here.]

It can be seen that from Monday till Wednesday the low solar irradiation is not sufficient to load the CES completely, whereas on the other days the CES is charged fully to a SOC of $99 \%$. At night, the storage is capable of supplying the load, and only on Tuesday morning energy is drawn from the grid (cyan). Furthermore, the performance of the prognosis-based operating strategy can be shown, as it prevents high feed-in peaks at noon by smoothing the charging process over the day time. Due to the grid feed-in limit of $50 \%$ the PV-power is curtailed (black) on Thursday, Saturday and Sunday, as the CES reached its' full capacity before the evening.

\subsubsection{Evaluation of the Operation Strategy based on Performance Indicators}

The performance indicators self-consumption ratio and self-supply ratio for all 5 CES are listed in Table 3. The indicators were calculated with (index PV) and without storage 
(index CES) in order to evaluate the influence of the CES. It can be seen clearly that the BSS increases the SCR and the SSR. The first row of the table shows the ratio of the PV systems connected to the CES $\mathrm{P}_{\mathrm{PV}}$ in $\mathrm{kW}_{\mathrm{p}}$ and yearly energy consumption of the load $\mathrm{E}_{\text {load }}$ in MWh, respectively.

[Table 3 about here.]

The influence of the dimensioning of the load and PV can be shown by the example of CES 5: In this case there is significantly more load connected to this CES than to the other storages, leading to the smallest increase of the self-consumption rate from $55 \%$ without $\mathrm{CES}\left(\mathrm{SCR}_{\mathrm{PV}}\right)$, to $60 \%$ with $\mathrm{CES}\left(\mathrm{SCR}_{\mathrm{CES}}\right)$. Vice versa the small load to $\mathrm{PV}$ ratio (CES1) results in the highest self-supply ratio with $\mathrm{CES} \mathrm{SSR}_{\mathrm{CES}}$ of $68 \%$. The curtailment loss ratio for all CES lies under the negligible level of less than $1 \%$. This is factor 3 to 7 smaller then the curtailment losses of the same operation strategy applied to a residential PV-storage system [17. The negligible curtailment losses and the big reduction potential of CES matches with the results of Zeh et al. who compared residential PV-storage system with CES 7].

\subsubsection{Analysis of the Grid Supportive Behaviour}

In the simplified battery model the influence of the reactive power provision on the SOC is not included. But as in the case of CES 1 the PCC is the same for the PCR and the self-consumption operation strategy the same voltage time-series applies and the same energy to recharge the BSS as in the PCR-case can be assumed. For a better comparison between the two BSS-applications this energy is traded in the CES case on the intra-day market as well and causes costs of 14 EUR per month for the provision of reactive power for one CES.

\subsection{Economic Comparison of the two Business Models}

The resulting cash-flows and net present values (NPV) for both business cases are presented in this section. As described before section 3.1), realistic frequency and grid parameters are used for the analysis of the PCR business case. For the CES cases the economic calculation is based on a load flow calculation of the model grid for one year. Although, the cash-flow and the NPV is calculated for all 5 CES only the results of the most profitable CES 1 are shown and discussed. The NPV of CES 1 is $6 \%$ higher as for the least profitable CES 5 for the theoretic best case.

\subsubsection{Cash-flows}

In Fig. 15 the annual cash flows without discount for the PCR and CES business case for one BSS prototype are depicted. To participate in the PCR market, a minimum of $1 M W_{p q}$ pre-qualified power must be offered. Furthermore, the (n-1)-criteria has to be fulfilled. This means that for the examined prototype a pool of seven BSS with an offered power of $175 \mathrm{~kW}$ per BSS has to be in service. The displayed cash flow corresponds to one of the seven BSS of the pool. The comparison of the revenues and costs shows that, despite the low efficiency of the VRFB system, the annual PCR revenues are more than twice as much as the considered expenditures.

[Fig. 15 about here.] 
In the self-consumption maximisation business case with the CES the revenues represent savings for the avoided electricity costs by self-consumption of the energy from the PV system. They amount to 25,100 EUR per year. To show the range of possible economic results, three best case levies and charges scenarios are calculated, as explained in section 3 . In analogy to the avoided electricity costs, the lost feed-in tariff is not a matter of incurred expenditures, but rather a loss of revenue as a result of self-consumption compared to lost feed-in enumerated with the FIT.

The EEG charge and the VAT (including commercial and corporation tax for CES), on the other hand, are actually incurred for the self-consumed electricity from the CES. As it can been seen in the range of costs of the CES cash flows for the three scenarios, the influence of the levies and charges is the most decisive parameter on profitability of the CES business cases. This leads to the conclusion that although the revenues are 4.5 times higher then the costs in theory (costs (1)), only in the self-consumption best case (costs $(2)$ ) there might be a profitable business case, whereas in the direct marketing case (costs (3)) no profit is earned. This result could be even worst as the OPEX are based on the smallest invest cost and could be higher by the factor of almost 5 if the CAPEX of the prototype were considered instead.

The costs for the provision of reactive power for the grid supportive behaviour of the BSS are included in the intra-day trading costs in both business models. In both cases the additional costs of the reactive power provision are less than $1 \%$ of the revenues. Moreover, the $50 \%$ limit for the CES can be neglected, as the resulting curtailed energy is also less than $1 \%$ of the revenue.

\subsubsection{Net present value}

The calculation and comparison of the net present values, as depicted in Fig. 16 , shows that none of the two business cases is currently profitable with the assumed parametersand the given BSS. For both business cases the investment costs listed in Table 1 are considered. Assuming the CAPEX of the SPF prototype, both business cases are far from profitable, hence this case is not displayed in the graph.

[Fig. 16 about here.]

The negative NPV is mainly due to the high investment costs, as in both business cases the net cash flow can be positive as shown in section 4.3 .1$.

The result for the PCR-case matches with current investigations according to which LiB-systems can be operated profitable at the PCR market under optimistic assumptions [3, 4, but for VRFB the investment costs have yet to fall [8]. The investment costs of VRFB technology would have to decline by $30 \%$ compared to the minimal CAPEX and by $60 \%$ compared to the realistic (average) CAPEX in order to achieve a positive net present value.

If the BSS is used as a CES to maximise the self-consumption, it can be seen in Fig. 16. that the specific invest cost do not have such a big impact on the NPV as in the PCR business case. Although theoretically it can be a profitable business case, if minimal invest costs are assumed (CES (1)), this would only apply in a post-FIT scenario without any charges and levies. In a realistic scenario under the current legal framework (CES $(2)$ ), in which the CES is used for self-consumption, the CAPEX would have to fall by $77 \%$ at least to earn profits. The direct marketing is not profitable with the analysed 
parameters, as the charges and levies are too high to achieve an positive NPV, even if the BSS has no invest cost. Several studies for CES with LiB show that under the current legal framework it is not possible to reach a positive NPV [5] 7 , but might become an alternative to residential home storage systems in a post-FIT era if the legal framework is adapted [6]. Due to the unfavourable legal framework for CES, a direct subsidy is currently discussed in Germany 80].

Even though, none of the two business cases is profitable for VRFB at the moment, the PCR business case could reach the break even in the years to come, as the lowest battery cell price for utility scale flow batteries could decrease by $48 \%$ from 2014 to 2020 [12].

\section{Conclusion}

In this paper the two most promising operation strategies for primary control reserve and maximisation of self-consumption, for a grid supportive vanadium redox flow battery are compared. For this purpose two battery models for a VRFB based on measurement data are presented. The operation strategy for the primary control business case was tested in the field and the corresponding battery model verified in a field test. Finally, the technical and economic results of the two business cases are analysed and compared. The main findings and contributions of the paper are:

- A detailed battery system model, for a VRFB which enables to calculate the state of charge for a given active and reactive power in 1-s time-steps is presented and implemented for the analysis of the PCR business case. It is validated together with the PCR operation strategy for a grid supportive VRFB in a field test.

- Based on the same data as the detailed vanadium redox flow system model, a simplified model for 1-min time-step calculations of the SOC, is presented and implemented in the operation strategy for the maximisation of self-consumption. This BSS model is embedded in a load flow calculation of the region in which the prototype is implemented in order to asses the economic profitability of a CES.

- A clear methodology for the operation strategy of a grid supportive VRFB which provides primary frequency control or maximises the self-conumption is presented. To ensure the grid supportive behaviour, an autonomous reactive power control based on a $\mathrm{Q}(\mathrm{V})$-characteristic is implemented.

- The model of the PCR-operation mode and the detailed VRFB model are used to calculate to most profitable parameters for the VRFB. These parameters were implemented in a prototype and tested in the field in a multi-week test period demonstrating that the BSS is able to provide a grid supportive PCR. Furthermore, the simulation of the PCR-strategy shows that the DOF have the potential to reduce the energy needed to recharge the BSS in order to provide PCR by approximately $20 \%$. Nonetheless, the monthly delta net revenues can only be raised by $2.1 \%$, as the energy costs to recharge the battery are much lower than the possible revenues on the PCR market. 
- For the maximisation of self-consumption an autonomous adaptive prognosis based operation strategy is implemented. The aim of this strategy is to minimise the daily feed-in energy and thus maximise the profit at the same time providing a peak shaving of $50 \%$ of the maximal PV power connected to the CES. The evaluation of this strategy via the performance indicators curtailment loss ratio, self-consumption ratio and self-supply ratio, shows that the SCR can be risen by $26 \%$ and the SSR by $23 \%$ compared to PV-systems with no storage. This could relief the higher voltage levels considerably, as the power is generated and consumed locally. Another result is, that this operation strategy operates close to the theoretic maximum, as the curtailment losses are smaller than $1 \%$. This is factor 3 to 7 smaller then the curtailment losses of the same operation strategy applied to a residential PV-storage system.

- It is shown that the reactive power provision and therefore the grid supportive behaviour does not lead to any significant additional costs for neither of the operation strategies.

- The profitability of the PCR business case is mainly determined by the investment cost and the PCR-market revenues. In order to break even under current conditions, the VRFB investment costs must be reduced by at least $30 \%$.

- As for the profitability of the self-consumption business case the invest costs, the price of the FIT and above all the incurring charges and levies are the most decisive factors. It is shown that this business case could already be profitable in theory, but due to the legal framework in place, the CAPEX of the VRFB have to fall by $77 \%$ in the best case to reach break even. If a direct marketing business case for self consumption is perused no profit can be earned as the incurring charges and levies lead to a negative cash-flow.

In conclusion, it is worth pointing out that VRFB may become economically feasible in Germany in the near future if they provide primary control reserve. Despite lower curtailment losses compared to residential PV storage systems, due to the unfavourable legal framework it is not clear whether community electricity storages applying selfconsumption maximisation will become feasible in the near future.

The most important contribution of this paper is that there is almost no negative impact on the two business cases if the BSS is operated in a grid supportive behaviour by providing reactive power control and/ or peak shaving additionally to its primary purpose.

\section{Acknowledgement}

This work was supported by the German Federal Ministry of Economics and Technology (BMWi) and the Projektträger Jülich GmbH (PTJ) within the framework of the project "SmartPowerFlow" (FKZ0325523A). The authors would also like the contributions of the research group Solar Storage Systems of the HTW Berlin. 


\section{References}

[1] Resch M, Bühler J, Klausen M, Sumper A, Impact of operation strategies of large scale battery systems on distribution grid planning in Germany, Renew. Sustain. Energy Rev. 74 (2017) 1042 1063. doi:10.1016/j.rser.2017.02.075

[2] Zeh A, Müller M, Naumann M, Hesse H, Jossen A, Witzmann R, Fundamentals of Using Battery Energy Storage Systems to Provide Primary Control Reserves in Germany, Batteries 2 (3) (2016) 29. doi:10.3390/batteries2030029

[3] Fleer J, Zurmühlen S, Badeda J, Stenzel P, Hake J.-F, Sauer D. U, Model-based Economic Assessment of Stationary Battery Systems Providing Primary Control Reserve, Energy Procedia 99 (2016) 11-24. doi:10.1016/j.egypro.2016.10.093

[4] Aundrup T, Beck H.-P, Becker A, Berthold A, Batteriespeicher in der Nieder- und Mittelspannungsebene - Anwendungen und Wirtschaftlichkeit sowie Auswirkungen auf die elektrischen Netze, Tech. rep., Energietechnische Gesellschaft im VDE (ETG) (2015).

[5] Jülch V, Thomsen J, Hatmann N, Junne T, Lea U, Arnold M, Betreibermodelle für Stromspeicher, Tech. rep., Fraunhofer ISE, IER Stuttgart, Compare Consulting (2016).

[6] Lachmann Y, Prahl O, Knösel M, Mühlbach J, Nau N, Papenheim J, Kubach M, Schellenberger M, Sebastian E, Schmidt P, Heller E, Strombank - Abschlussbericht, Tech. rep., MVV, IER Stuttgart, Netrion, adstec (2017).

[7] Zeh A, Rau M, Witzmann R, Comparison of decentralised and centralised grid-compatible battery storage systems in distribution grids with high PV penetration, in: Prog. Photovoltaics Res. Appl., 2014, p. 11. doi:10.1002/pip.2566

[8] Malhotra A, Battke B, Beuse M, Stephan A, Schmidt T, Use cases for stationary battery technologies: A review of the literature and existing projects, Renew. Sustain. Energy Rev. 705721 doi:10.1016/j.rser.2015.11.085

[9] Gaudchau E, Resch M, Zeh A, Quartierspeicher: Definition, rechtlicher Rahmen und Perspektiven, Ökologisches Wirtschaften - Fachzeitschrift 31 (2) (2016) 26. doi:10.14512/OEW310226.

[10] Parra D, Gillott M, Norman S. A, Walker G. S, Optimum community energy storage system for PV energy time-shift, Appl. Energy 137 (2015) 576-587. doi:10.1016/j.apenergy.2014.08.060

[11] Möller C, Kuhnke K, Reckzugel M, Pfisterer H.-J, Rosenberger S, Energy storage potential in the Northern German region Osnabrück-Steinfurt, in: 2016 Int. Energy Sustain. Conf., IEEE, 2016, pp. 1-7. doi:10.1109/IESC.2016.7569497

[12] Kempener R, Borden E, Battery Storage for Renewables: Market Status and Technology Outlook, Tech. rep., International Renewable Energy Agency (IRENA) (2015).

[13] Betzin C, Wolfschmidt H, Luther M, Electrical operation behavior and energy efficiency of battery systems in a virtual storage power plant for primary control reserve, Int. J. Electr. Power Energy Syst. 97 (February 2017) (2018) 138-145. doi:10.1016/j.ijepes.2017.10.038

[14] Agricola A, Höflich B, Richard P, Völker J, Rehtanz C, dena-Verteilnetzstudie. Ausbau- und Innovationsbedarf der Stromverteilnetze in Deutschland bis 2030., Tech. rep., Deutsche Energie-Agentur GmbH (dena), Berlin (2012).

[15] Hallberg P, Rios-Alba J, Birkner P, Hankan F, Kroll A, Decentralised Storage: Impact on Future Distribution Grids, Tech. rep., Union of the Electricity Industry (EURELECTRIC) (2012).

[16] Resch M, Ramadhani B, Bühler J, Sumper A, Comparison of control strategies of residential PV storage systems, in: 9th Int. Renew. Energy Storage Conf. (IRES 2015), 2015, p. 18. doi:10.13140/ RG.2.1.3668.2084

[17] Rascon O. C, Resch M, Bühler J, Sumper A, Techno-economic comparison of a schedule-based and a forecast-based control strategy for residential photovoltaic storage systems in Germany, Electr. Eng. 98 (4) (2016) 375-383. doi:10.1007/s00202-016-0429-7

[18] Bühler J, Resch M, Wiemann J, Twele J, Lebenszyklusanalyse von Großbatterien am deutschen Regelenergiemarkt, in: 9. Int. Energiewirtschaftstagung, 2015, p. 44. doi:10.13140/RG.2.1.4454. 6400 .

[19] Federal Ministry of Economic Affairs and Energy (BMWi), SmartPowerFlow, [Accessed 1-6-2017]. URL http://forschung-energiespeicher.info/batterie-im-netz/projektliste/projekteinzelansicht/104/Fluessigspeicher\{_\}vereinfacht\{_\}Netzausbau/

[20] Rascon O. C, Resch M, Schachler B, Buhler J, Sumper A, Increasing the hosting capacity of distribution grids by implementing residential PV storage systems and reactive power control, in: 2016 13th Int. Conf. Eur. Energy Mark., IEEE, 2016, pp. 1-5. doi:10.1109/EEM.2016.7521338

[21] Zheng Q, Li X, Cheng Y, Ning G, Xing F, Zhang H, Development and perspective in vanadium 
flow battery modeling, Appl. Energy 132 (2014) 254-266. doi:10.1016/j.apenergy.2014.06.077 URL http://dx.doi.org/10.1016/j.apenergy.2014.06.077

[22] Tang A, Bao J, Skyllas-Kazacos M, Studies on pressure losses and flow rate optimization in vanadium redox flow battery, J. Power Sources 248 (2014) 154-162. doi:10.1016/j.jpowsour.2013.09. 071

[23] König S, Suriyah M. R, Leibfried T, Innovative model-based flow rate optimization for vanadium redox flow batteries, J. Power Sources 333 (2016) 134-144. doi:10.1016/j.jpowsour.2016.09.147

[24] Turker B, Arroyo Klein S, Hammer E.-M, Lenz B, Komsiyska L, Modeling a vanadium redox flow battery system for large scale applications, Energy Convers. Manag. 66 (2013) 26-32. doi: 10.1016/j.enconman.2012.09.009

[25] Qiu G, Joshi A. S, Dennison C. R, Knehr K. W, Kumbur E. C, Sun Y, 3-D pore-scale resolved model for coupled species/charge/fluid transport in a vanadium redox flow battery, Electrochim. Acta 64 (2012) 46-64. doi:10.1016/j.electacta.2011.12.065

[26] Frenkel D, Preface to the Second Edition, in: Underst. Mol. Simul., Elsevier, 2002, pp. xiii-xiv. doi:10.1016/B978-012267351-1/50000-6

[27] Weniger J, Bergner J, Beier D, Jakobi M, Tjaden T, Quaschning V, Grid Feed-in Behavior of Distributed Pv Battery Systems, in: 31st Eur. PV Sol. Energy Conf. Exhib., Hamburg, 2015, pp. 1603-1606.

[28] Alotto P, Guarnieri M, Moro F, Redox flow batteries for the storage of renewable energy: A review, Renew. Sustain. Energy Rev. 29 (2014) 325-335. doi:10.1016/j.rser.2013.08.001

[29] Rösinger T, SMA Solar Technology AG, personal communication (Email), 04 May, 2017.

[30] Strauch N, Einsatz von Energiespeicher-Technologien in Inselsystemen mit hohem Anteil Erneuerbarer Energien, Phd thesis, TU Darmstadt (2013).

[31] Bühler J, Instandhaltungs- und Erneuerungsoptimierung von städtischen Mittelspannungsnetzen, Phd thesis, TU Darmstadt (2013).

[32] Pawel I, The Cost of Storage How to Calculate the Levelized Cost of Stored Energy (LCOE) and Applications to Renewable Energy Generation, Energy Procedia 68-77doi:10.1016/j.egypro. 2014.01.159

[33] ENTSO-E Operation Handbook (Policy 1), European Network of Transmission System Operators (ENTSO-E) (2009).

[34] Network Code on Load-Frequency Control and Reserves, European Network of Transmission System Operators (ENTSO-E) (2013).

[35] Guideline on Transmission System Operation (SO GL) - Draft, European Network of Transmission System Operators (ENTSO-E) (2016).

[36] Guideline on Electricity Balancing (EB GL) - Draft, European Network of Transmission System Operators (ENTSO-E) (2016).

[37] Gesetz über die Elektrizitäts-und Gasversorgung (Energiewirtschaftsgesetz-EnWG), German Bundestag (2005).

[38] Verordnung über den Zugang zu Elektrizitätsversorgungsnetzen (Stromnetzzugangsverordnung StromNZV), Federal Ministery of Justice and Consumer Protection (2005).

[39] Renewable Energy Act (Erneuerbare - Energien - Gesetz - EEG 2014), Federal Ministry of Justice and Consumer Protection (2014).

[40] TransmissionCode 2007 - Netz- und Systemregeln der deutschen Übertragungsnetzbetreiber, Tech. rep., Association of German Grid Operators (VDN) (2007).

[41] PRL-Rahmenvertrag, German TSO (2013).

[42] Freiheitsgrade der PRL-Ebringung, German TSO (2014).

[43] Anforderungen an die Speicherkapazität bei Batterien für die Primärregelleistung, German TSO (2015).

[44] Otte M, Patt J, Lück J, Beschluss BK6-10-097, Federal Network Agency (BNetzA) (2011).

[45] Díaz-González F, Hau M, Sumper A, Gomis-Bellmunt O, Participation of wind power plants in system frequency control: Review of grid code requirements and control methods, Renew. Sustain. Energy Rev. 34 (2014) 551-564. doi:10.1016/j.rser.2014.03.040.

[46] Swider D. J, Handel an Regelenergie- und Spotmärkten - Methoden zur Entscheidungsunterstützung für Netz- und Kraftwerksbetreiber, Phd thesis, Univertsity Stuttgart (2006).

[47] Hirth L, Ziegenhagen I, Balancing power and variable renewables: Three links, Renew. Sustain. Energy Rev. 50 (2015) 1035-1051. doi:10.1016/j.rser.2015.04.180

[48] regelleistung.net Germant TSO, [Accessed 1-6-2017]. URL https://www.regelleistung.net/ext/

[49] Schlossarczyk M, Wie viel Batterigroßspeicher verträgt der Primärregelleistungsmarkt?, Tech. rep., 
Enervis energy advisors (2016).

[50] Durchschnittliche Preise in Deutschland. Energy Charts Fraunhofer ISE, [Accessed 2-4-2016]. URL www .energy-charts . de

[51] Ruhland A, Nachladen: Intraday Ablauf und Kostenschätzungen, personal communication (Email), 01 May, 2016.

[52] Fleer J, Stenzel P, Impact analysis of different operation strategies for battery energy storage systems providing primary control reserve, J. Energy Storagedoi:http://dx.doi.org/10.1016/j. est.2016.02.003

[53] Bourwieg K, Eine regulatorische Einordnung von Stromspeichern im aktuellen Rechtsrahmen, Tech. rep., Federal Ministry of Economic Affairs and Energy (BMWi) (2015).

[54] Entgelte für Messstellenbetrieb, Messung und Abrechnung bei Energieentnahme und -einspeisung mittels Lastgangmessung, Preisblatt 4, LVN (2016).

[55] Beschreibung von Regelleistungskonzepten und Regelleistungsmarkt, Tech. rep., Consentec, 50Hertz Transmission GmbH (2014).

[56] Hollinger R, Diazgranados L. M, Braam F, Erge T, Bopp G, Engel B, Distributed solar battery systems providing primary control reserve, IET Renew. Power Gener. 10 (1) (2016) 63-70. doi: 10.1049/iet-rpg.2015.0147

[57] Moseley P. T, Garche J, Electrochemical Eenrgy Storage for Renewable Sources and Grid Balancing, 2015. doi:10.1016/B978-0-444-62616-5.00010-3

[58] Produkte: Intraday Auktion., European Power Exchange (EPEX), [Accessed 1-4-2017] (2016). URL https://www.epexspot.com/de/produkte/intradayauction/deutschland

[59] Voltage characteristics of electricity supplied by public distribution networks; German version EN 50160: 2010 + Cor.: 2010, German Institute for Standardisation (DIN) (2011).

[60] Stetz T, Autonomous Voltage Control Strategies in Distribution Grids with Photovoltaic Systems: Technical and Economic Assessment, Phd thesis, University of Kassel (2014).

[61] Engel B, Laudahn S, Marggraf O, Schnettler A, Vergleich von technischer Wirksamkeit sowie Wirtschaftlichkeit zeitnah verfügbarer Verfahren zur Sicherung der statischen Spannungshaltung in Niederspannungsnetzen mit starker dezentraler Einspeisung, Tech. rep., TU Braunschweig, RWTH Aachen, TU München, FGH (2014).

[62] Leitfaden zur Eigenversorgung, Tech. rep., Federal Network Agency (BNetzA) (2016).

[63] Erneuerbare Energien und das EEG: Zahlen, Fakten, Grafiken (2015), Tech. rep., Berlin, German Association of the Energy and Water Industry (BDEW) (2015).

[64] Bestimmung der Förderssätze für Fotovoltaikanlagen §31 EEG 2014 für die Kalendermonate Oktober 2015, November 2015 und Dezember 2015, Federal Network Agency (BNetzA) (2015).

[65] Haller M, Loreck C, Graichen V, Die Entwicklung der EEG-Kosten bis 2035, Tech. rep., Öko-Institut e.V (2015).

[66] Fünfgeld C, Tiedemann R, Anwendung der Repräsentativen VDEW-Lastprofile step by step, VDEW Mater. M-05/2000 (2000) 34

[67] Tjaden T, Joseph B, Quaschning V, Repräsentative elektrische Lastprofile für Wohngebäude in Deutschland auf 1-sekündiger Datenbasis (2015). doi:10.13140/RG.2.1.5112.0080

[68] Wirth G, Modellierung der Netzeinflüsse von Photovoltaikanlagen unter Verwendung meteorologischer Parameter, Phd thesis, Carl von Ossietzky university Oldenburg (2014).

[69] Nykamp S, Integrating Renewables in Distribution Grids : Storage, regulation and the interaction of different stakeholders in future grids, Phd thesis, University of Twente (2013). doi:10.3990/1. 9789036500579

[70] Weniger J, Tjaden T, Quaschning V, Sizing and grid integration of residential PV battery systems, in: 8th Int. Renew. Energy Storage Conf. Exhib. (IRES 2013), 2013.

[71] Bergner J, Weniger J, Tjaden T, Quaschning V, Feed-in Power Limitation of Grid-Connected PV Battery Systems with Autonomous Forecast-Based Operation Strategies, in: 29th Eur. PV Sol. Energy Conf. Exhib., Amsterdam, 2014.

[72] Weniger J, Bergner J, Quaschning V, Integration of PV power and load forecasts into the operation of residential PV battery systems, in: 4th Sol. Integr. Work., 2014, pp. 383-390.

[73] Genoese F, Modellgestützte Bedarfs- und Wirtschaftlichkeitsanalyse von Energiespeichern zur Integration erneuerbarer Energien in Deutschland, Phd thesis, University of Karlsruhe (2013).

[74] Battke B, Schmidt T. S, Grosspietsch D, Hoffmann V. H, A review and probabilistic model of lifecycle costs of stationary batteries in multiple applications, Renew. Sustain. Energy Rev. 25 (2013) 240-250. doi:10.1016/j.rser.2013.04.023

[75] Wietschel M, Energietechnologien der Zukunft. Erzeugung, Speicher, Effizienz und Netze, Springer Fachmedien, Wiesbaden, 2015. 
[76] Hochloff P, Meyer B, von Appen J, Wendorff M, Trost T, Abschlussbericht Metastudie "Energiespeicher", Tech. rep., Fraunhofer UMSICHT and Fraunhofer IWES (2014).

[77] Sauer D. U, Lunz B, Magnor D, Marktanreizprogramm für dezentrale Speicher insbesondere für PV-Strom, Tech. rep., RWTH Aachen (2013).

[78] Akhil A. A, Huff G, Currier A. B, Kaun B. C, Rastler D. M, Chen S. B, Bradshaw D. T, Gauntlett W. D, Electricity storage handbook, Tech. rep., Sandia National Laboratories (2013).

[79] Sterner M, Stadler I, Energiespeicher - Bedarf, Technologien, Integration, Springer Berlin Heidelberg, Berlin, Heidelberg, 2014. doi:10.1007/978-3-642-37380-0.

[80] Koepp M, Krampe L, Marco W, Heidrun S, Mieterstrom - Rechtliche Einordnung, Organisationsformen, Potenziale und Wirtschaftlichkeit von Mieterstrommodellen (MSM), Tech. rep., Federal Ministry of Economic Affairs and Energy (BMWi) (2017). 


\section{List of Figures}

\begin{tabular}{|c|c|}
\hline 1 & quadrant operation mode of the BSS inverter (load perspective).Note \\
\hline & for the editor: one column Fig. $\ldots \ldots \ldots \ldots$. . . . . . . . . . . . \\
\hline 2 & Measured active power dependent inverter losses (load perspective). Note \\
\hline & 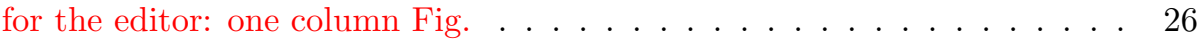 \\
\hline 3 & Measured inverter losses at reactive power provision (load perspective). \\
\hline & Note for the editor: one column Fig. . . . . . . . . . . . . . . . . \\
\hline 4 & Measured battery charging curves. Note for the editor: one column Fig. \\
\hline 5 & Measured battery discharging curves. Note for the editor: one column Fig. \\
\hline 6 & Measured round trip efficiency curve and fitted BSS model. Note for the \\
\hline & editor: one column Fig. . . . . . . . . . . . . . . . . . . . . . . . . . . . . \\
\hline 7 & Schematic of the variable operation strategy parameters for the PCR- \\
\hline & model. Note for the editor: one column Fig. $\quad$. . . . . . . . . . . . . . . . \\
\hline 8 & Schematic model of the operating strategy for a grid supportive battery \\
\hline & providing PCR. Note for the editor: one column Fig. . . . . . . . . . . . . \\
\hline 9 & $\mathrm{Q}(\mathrm{V})$-characteristic used for the reactive power control. Note for the edi- \\
\hline & tor: one column Fig. $\quad$. . . . . . . . . . . . . . . . . . . . . . . . . . . \\
\hline 10 & Charges, levies and taxes for CES in 2016, based on [5]. Note for the \\
\hline & editor: one column Fig. . . . . . . . . . . . . . . . . . . . . . . . . . . . . \\
\hline 11 & Load and generator assignment of the 5 CES in the village of the SPF \\
\hline & project. Note for the editor: one column Fig.. . . . . . . . . . . . . . . . \\
\hline 12 & rpt from the field test of the grid-supportive PCR operating strategy, \\
\hline & 03.-17.08.16. Upper graph: provided active $\mathrm{P}_{\mathrm{AC}}$ and reactive power $\mathrm{Q}(\mathrm{V})$ \\
\hline & of the BSS and frequency dependant PCR-power P(f) (generator perspec- \\
\hline & raph: Measured and simulated SOC and correction limits. \\
\hline & Note for the editor: two column Fig. $\ldots \ldots \ldots \ldots$ \\
\hline 13 & l of the DOF and energy demand of the voltage control. \\
\hline & Note for the editor: one column Fig. . . . . . . . . . . . . . . . . . \\
\hline 14 & is-/charging of CES 1 for the exemplary week with the \\
\hline & 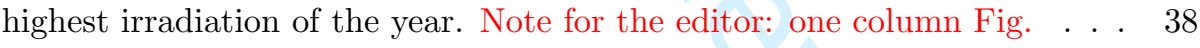 \\
\hline 15 & Cash-flows of both business cases. Note for the editor: one column Fig. . \\
\hline & plications: PCR and CES. Note for the editor: \\
\hline
\end{tabular}




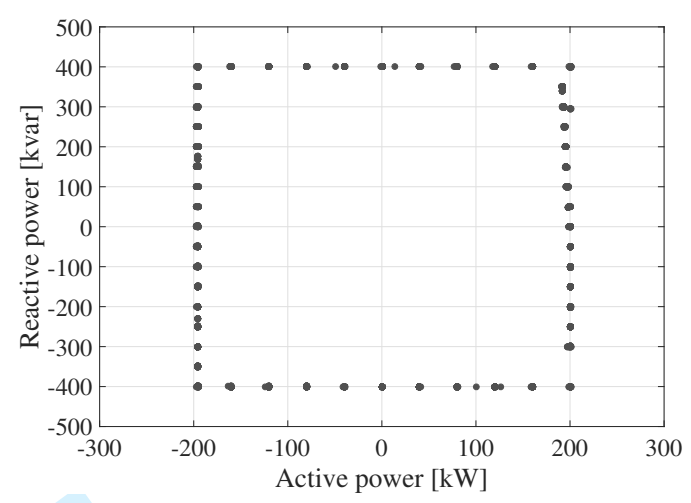

Fig. 1: 4-quadrant operation mode of the BSS inverter (load perspective).Note for the editor: one column Fig. 


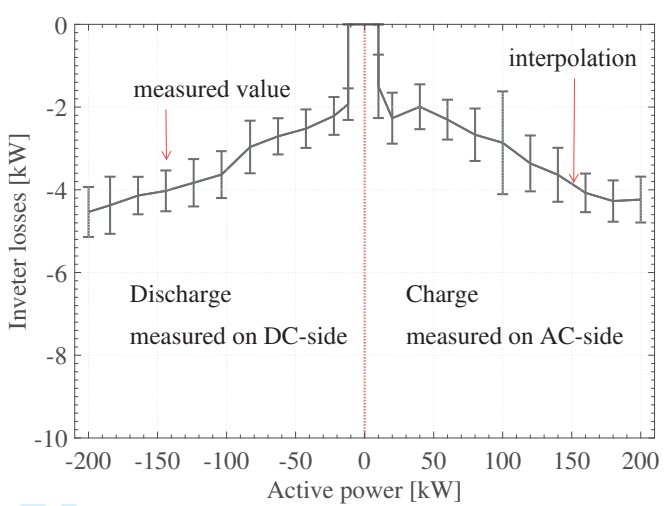

Fig. 2: Measured active power dependent inverter losses (load perspective). Note for the editor: one column Fig. 


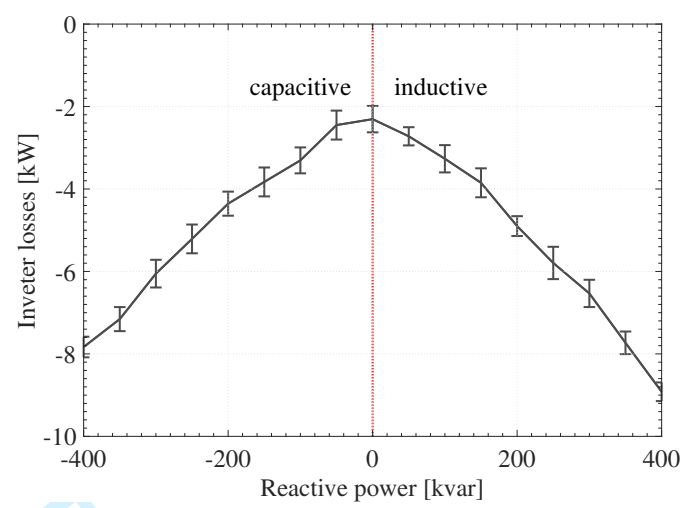

Fig. 3: Measured inverter losses at reactive power provision (load perspective). Note for the editor: one column Fig. 


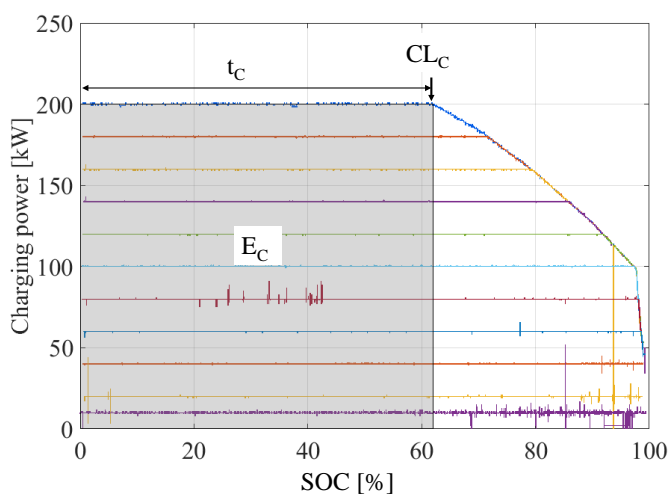

Fig. 4: Measured battery charging curves. Note for the editor: one column Fig. 


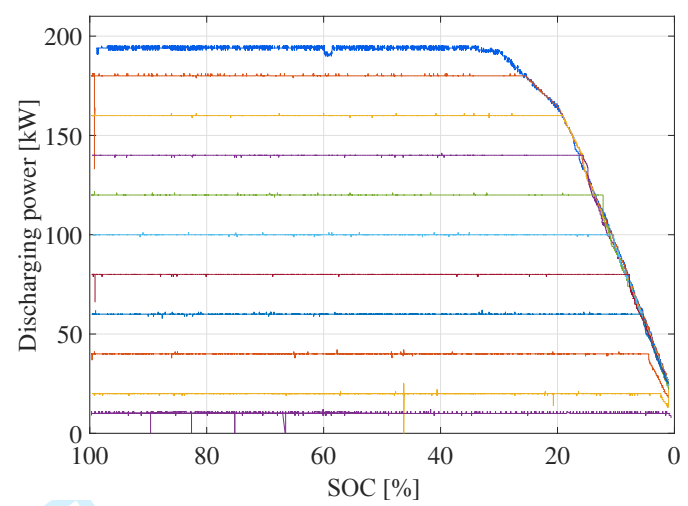

Fig. 5: Measured battery discharging curves. Note for the editor: one column Fig. 


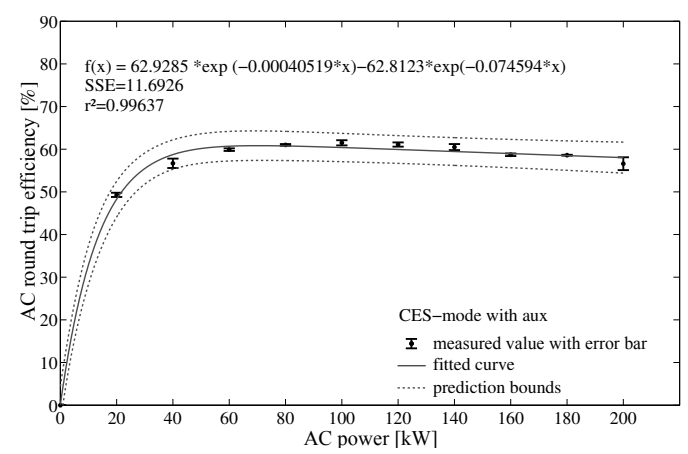

Fig. 6: Measured round trip efficiency curve and fitted BSS model. Note for the editor: one column Fig. 

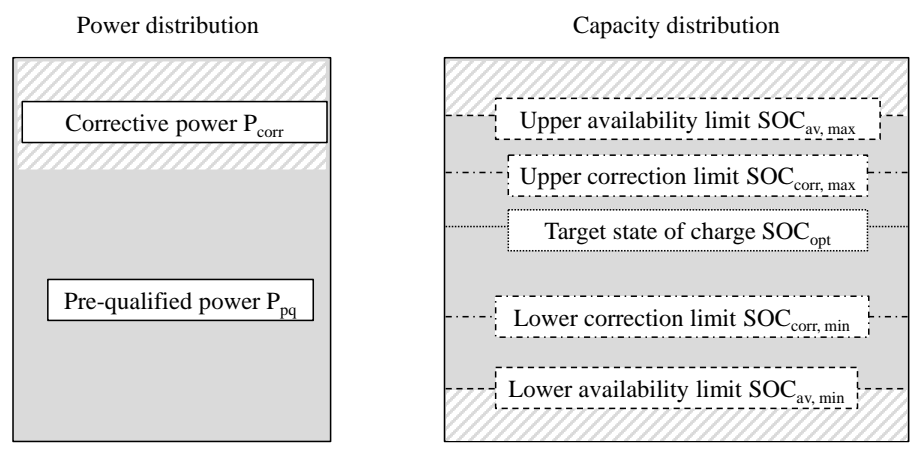

Fig. 7: Schematic of the variable operation strategy parameters for the PCR-model. Note for the editor: one column Fig. 


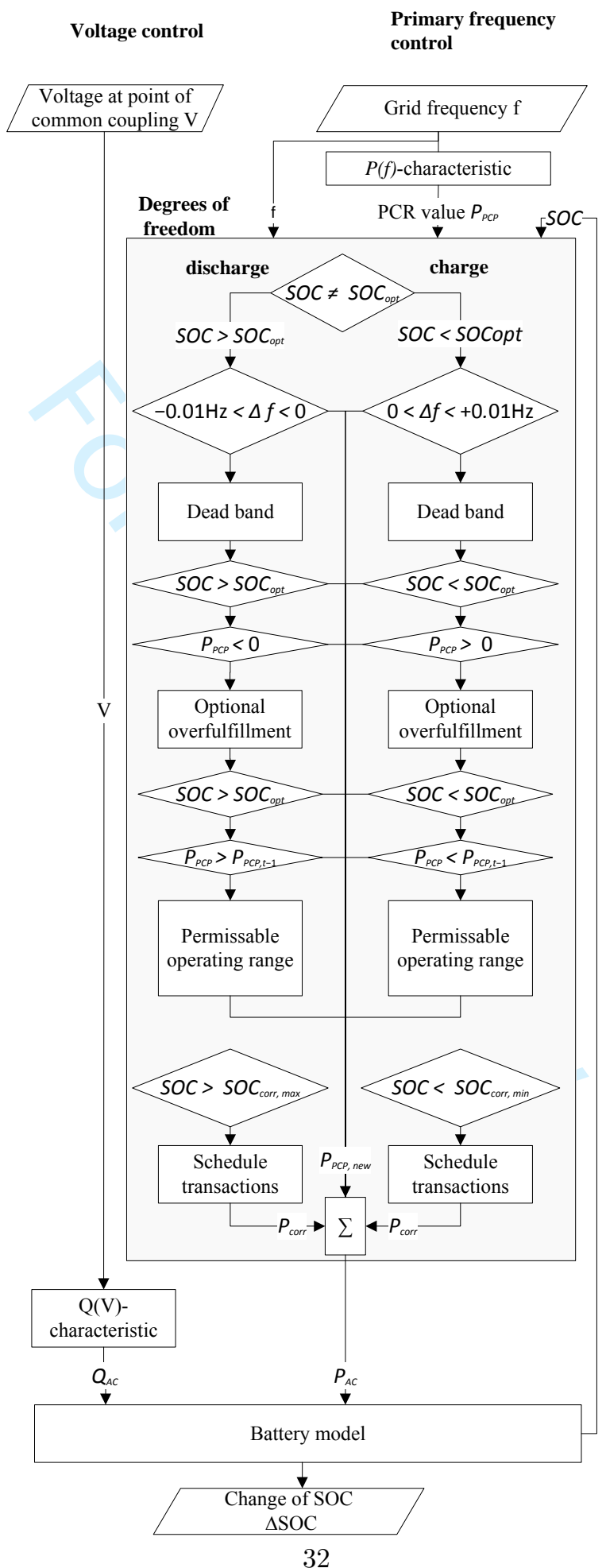

Fig. 8: Schematic model of the operating strategy for a grid supportive battery providing PCR. Note for the editor: one column Fig. 


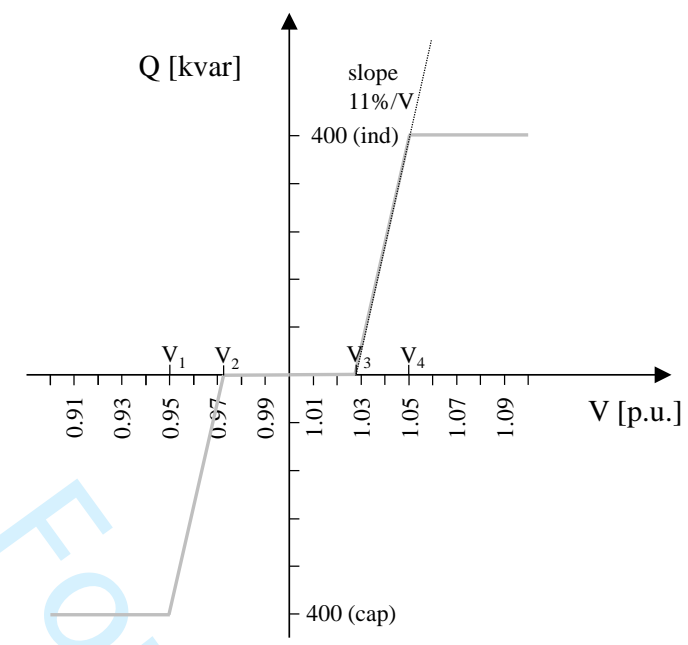

Fig. 9: $Q(V)$-characteristic used for the reactive power control. Note for the editor: one column Fig. 


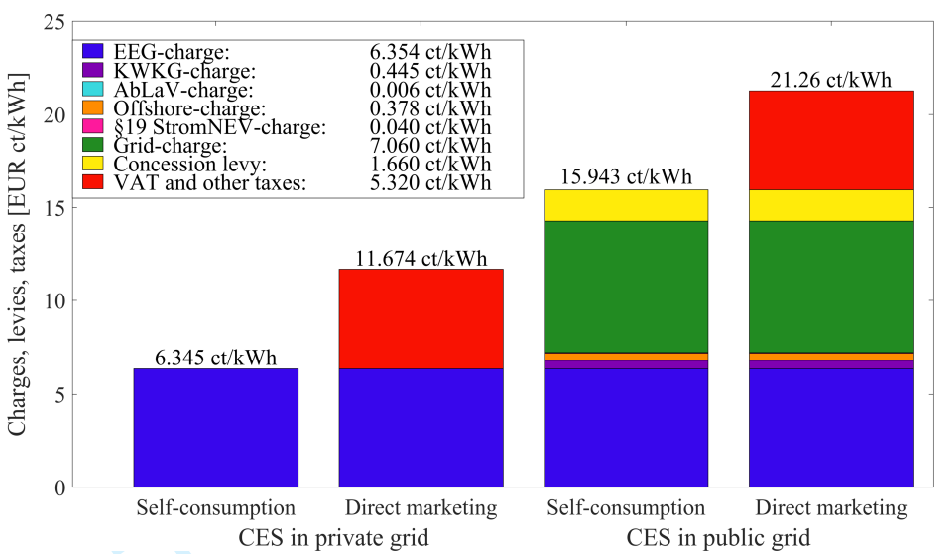

Fig. 10: Charges, levies and taxes for CES in 2016, based on [5. Note for the editor: one column Fig. 


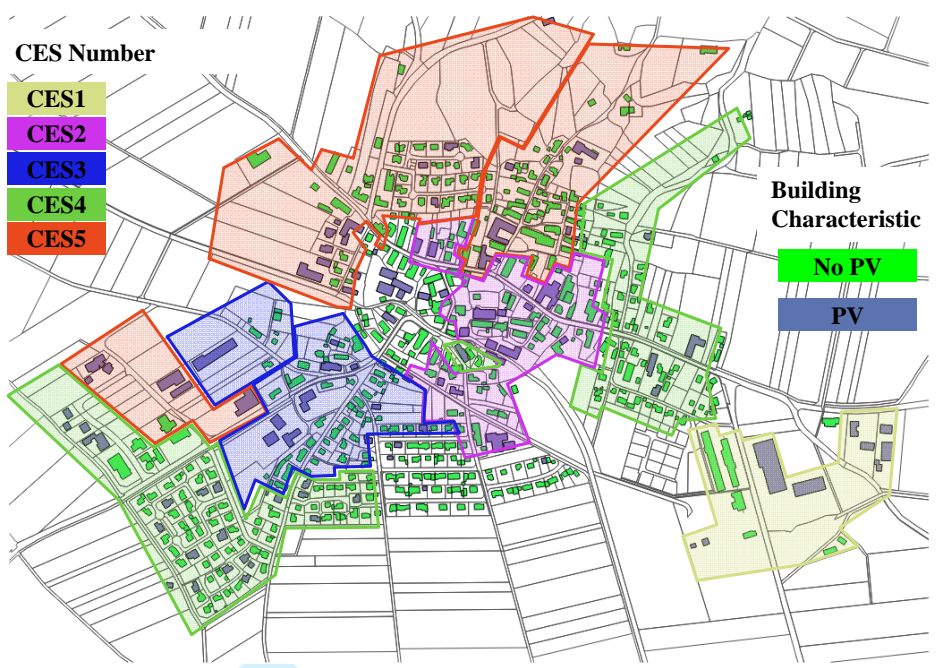

Fig. 11: Load and generator assignment of the 5 CES in the village of the SPF project. Note for the editor: one column Fig. 

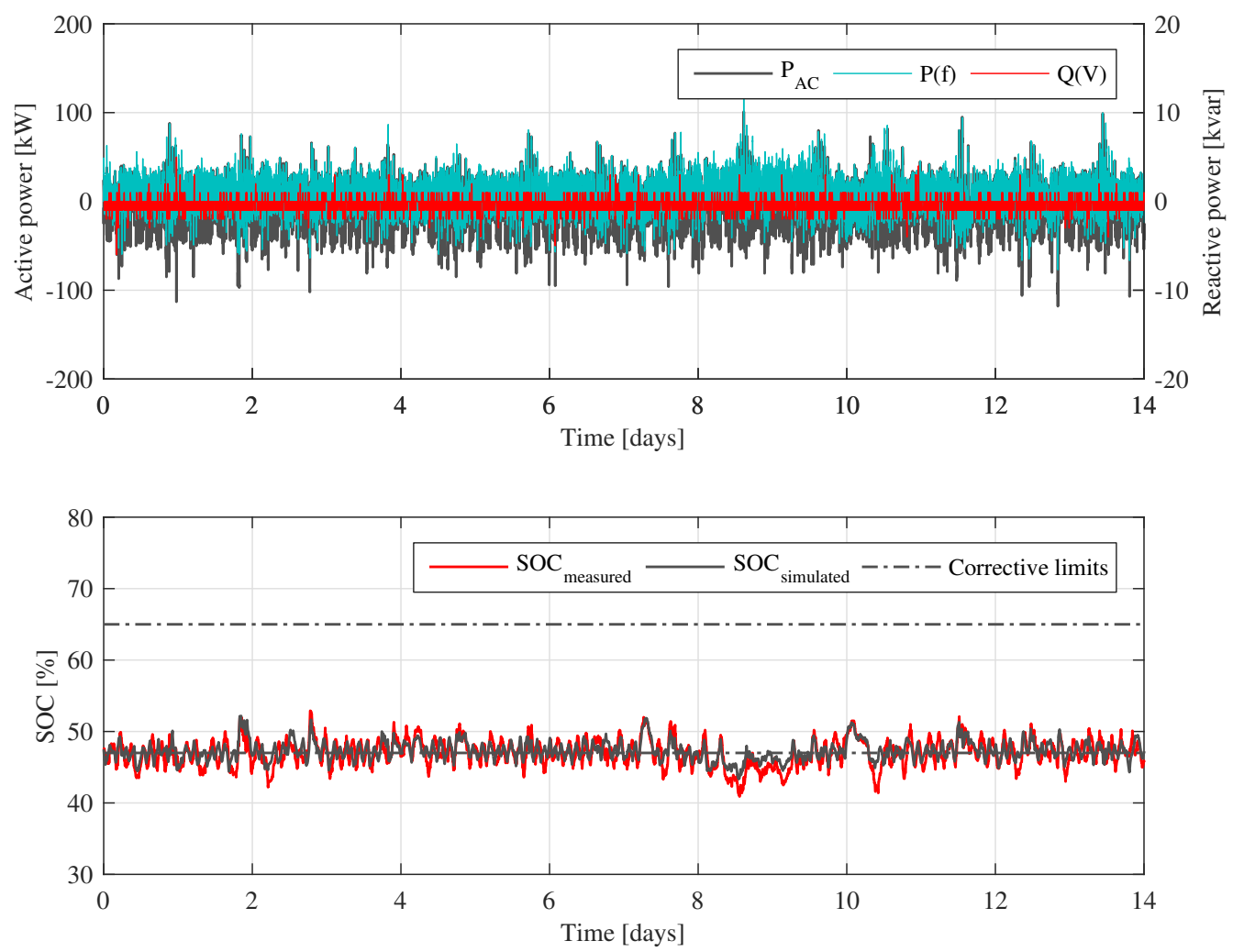

Fig. 12: Excerpt from the field test of the grid-supportive PCR operating strategy, 03.-17.08.16. Upper graph: provided active $\mathrm{P}_{\mathrm{AC}}$ and reactive power $\mathrm{Q}(\mathrm{V})$ of the BSS and frequency dependant $\mathrm{PCR}$-power $\mathrm{P}(\mathrm{f})$ (generator perspective). Lower graph: Measured and simulated SOC and correction limits. Note for the editor: two column Fig. 


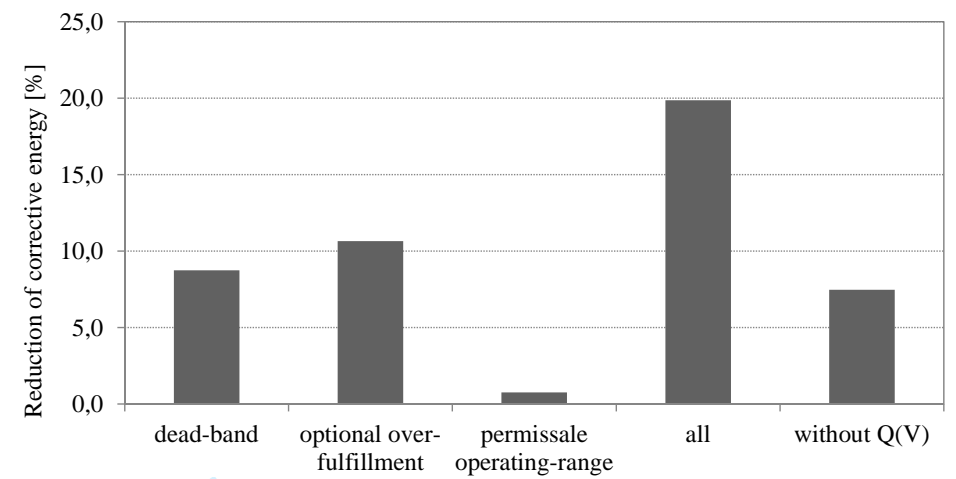

Fig. 13: Reduction potential of the DOF and energy demand of the voltage control. Note for the editor: one column Fig. 

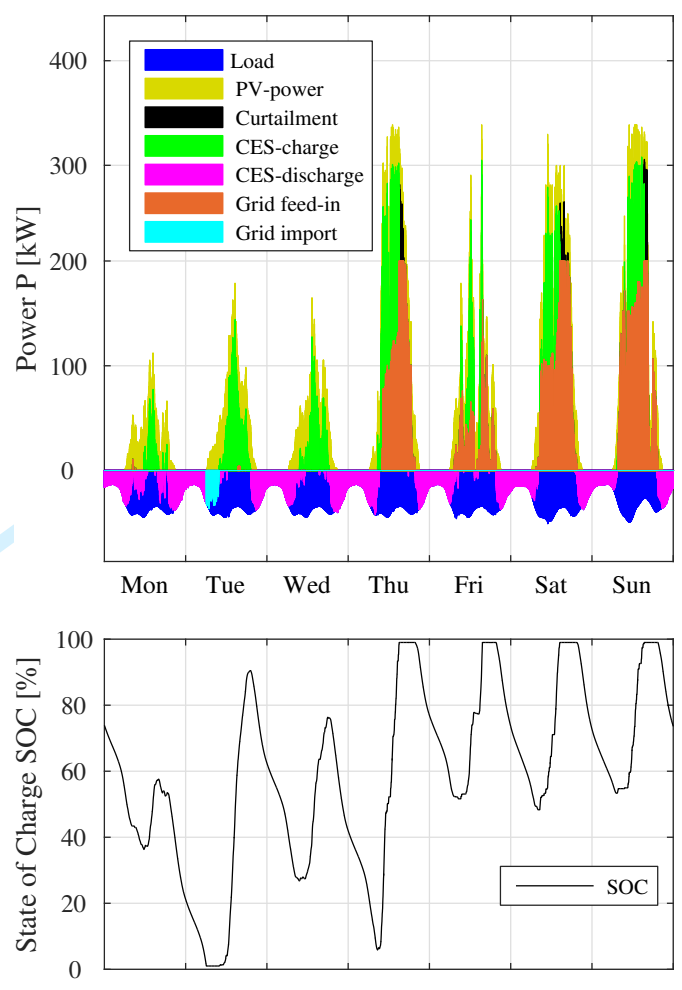

Week with highest irradiation of the year

Fig. 14: Power flows and dis-/charging of CES 1 for the exemplary week with the highest irradiation of the year. Note for the editor: one column Fig. 

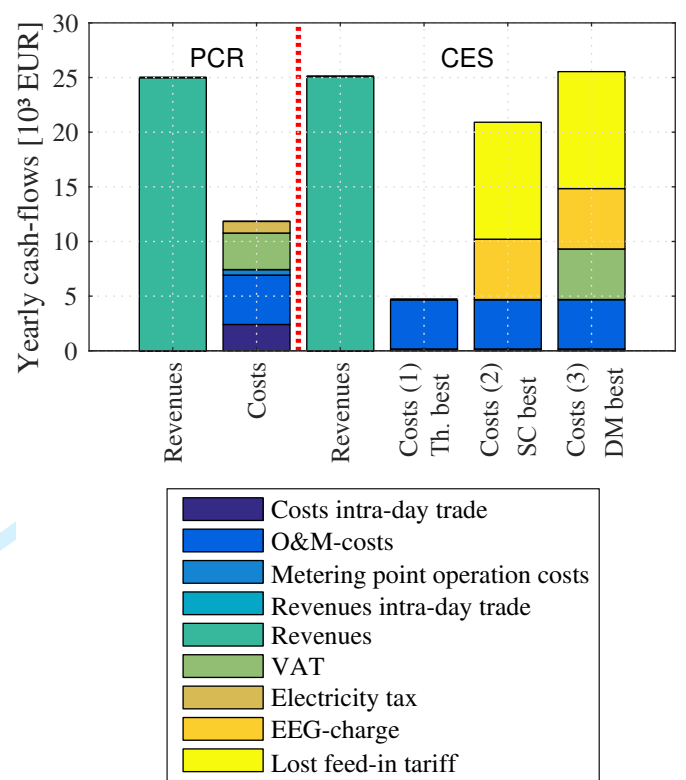

Fig. 15: Cash-flows of both business cases. Note for the editor: one column Fig. 


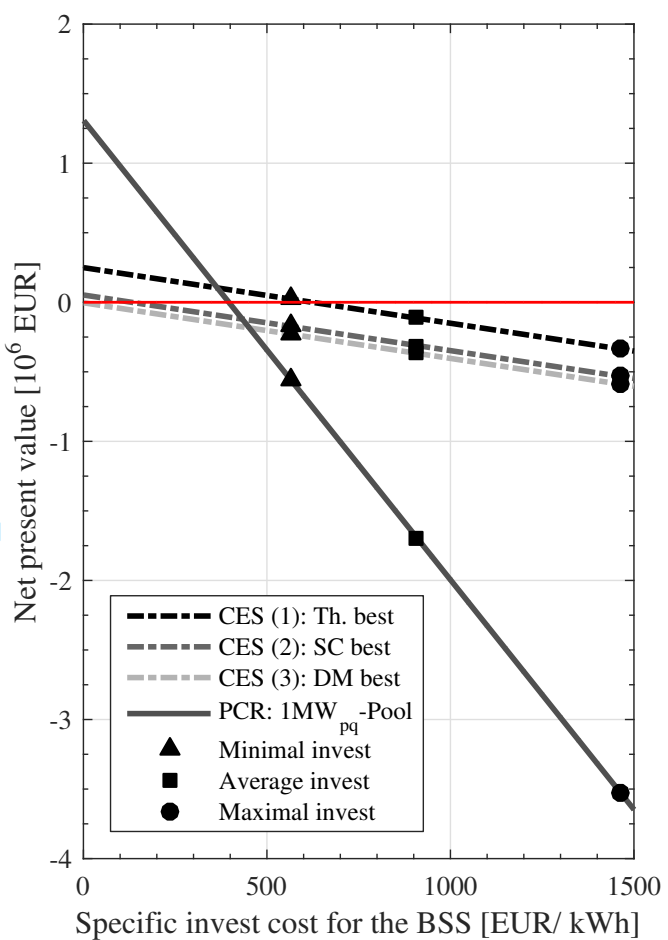

Fig. 16: Net present value of both applications: PCR and CES. Note for the editor: one column Fig. 


\section{List of Tables}

1 Minimal, average and maximal specific investment costs for a VRF BSS with $200 \mathrm{~kW} / 400 \mathrm{kWh}$, based on 73 [74 77 [78 . . . . . . . . . . . . . . . 42

2 Optimal parameters of the PCR operation strategy. . . . . . . . . . . . . 43

$3 \quad$ Sizing and calculated performance indicators of the CES. . . . . . . . . . 44 
Table 1: Minimal, average and maximal specific investment costs for a VRF BSS with $200 \mathrm{~kW} / 400 \mathrm{kWh}$, based on 73$] 74,77,78]$.

\begin{tabular}{lllll}
\hline & \multicolumn{3}{c}{ Commercial product } & Prototype \\
& $\min$. & av. & $\max$. & SPF \\
\hline Cost $\left[\frac{E U R}{k W h}\right]$ & 565 & 908 & 1464 & 2422 \\
\hline
\end{tabular}


Table 2: Optimal parameters of the PCR operation strategy.

\begin{tabular}{ll}
\hline Parameter & Value \\
\hline Pre-qualified power & $175 \mathrm{~kW}$ \\
Corrective power & $25 \mathrm{~kW}$ \\
Target value & $60 \%$ \\
Upper corrective limit & $65 \%$ \\
Lower corrective limit & $47 \%$ \\
Upper availability limit & $72 \%$ \\
Lower availability limit & $22 \%$ \\
\hline
\end{tabular}


Table 3: Sizing and calculated performance indicators of the CES.

\begin{tabular}{lccccc}
\hline & CES 1 & CES 2 & CES 3 & CES 4 & CES 5 \\
\hline $\mathrm{P}_{\mathrm{PV}}: \mathrm{E}_{\text {load }}$ & $1.2: 1$ & $1.1: 1.1$ & $0.9: 0.9$ & $0.9: 1.1$ & $1: 1.6$ \\
$\mathrm{SCR}_{\mathrm{PV}}[\%]$ & 33 & 41 & 34 & 37 & 55 \\
$\mathrm{SCR}_{\mathrm{CES}}[\%]$ & 59 & 52 & 54 & 69 & 60 \\
$\mathrm{SSR}_{\mathrm{PV}}[\%]$ & 45 & 44 & 45 & 43 & 43 \\
$\mathrm{SSR}_{\mathrm{CES}}[\%]$ & 68 & 63 & 67 & 63 & 54 \\
\hline
\end{tabular}

